\title{
Modelling heating and cooling energy demand for building stock using a hybrid approach
}

Article

Accepted Version

$\mathrm{Li}, \mathrm{X}$. and Yao, R. (2021) Modelling heating and cooling energy demand for building stock using a hybrid approach. Energy and Buildings, 235. 110740. ISSN 0378-7788 doi:

https://doi.org/10.1016/j.enbuild.2021.110740 Available at https://centaur.reading.ac.uk/98368/

It is advisable to refer to the publisher's version if you intend to cite from the work. See Guidance on citing.

Published version at: http://dx.doi.org/10.1016/j.enbuild.2021.110740

To link to this article DOI: http://dx.doi.org/10.1016/j.enbuild.2021.110740

Publisher: Elsevier

All outputs in CentAUR are protected by Intellectual Property Rights law, including copyright law. Copyright and IPR is retained by the creators or other copyright holders. Terms and conditions for use of this material are defined in the End User Agreement.

www.reading.ac.uk/centaur

\section{CentAUR}


Central Archive at the University of Reading

Reading's research outputs online 


\section{Modelling heating and cooling energy}

2 demand for building stock using a hybrid

3 approach

4 Xinyi $\mathrm{Li}^{1,2^{*}}$, Runming Yao ${ }^{2,3}$

$5{ }^{1,}$ Department of Civil and Structural Engineering, University of Sheffield, Sheffield,

6 S1 3JD, UK;

$7 \quad$ 2, Joint International Laboratory of Green Buildings and Built Environments, Ministry

8 of Education, Chongqing University, Chongqing, 400045, China;

$9{ }^{3}$ School of the Built Environment, University of Reading, Whiteknights, Reading,

10 Whiteknights PO Box 219, RG6 6AW, UK;

11

$12 \quad$ Highlights

13 - A hybrid approach for building stock energy prediction

14 - An energy prediction model for both residential and non-residential buildings

15 - Prediction performance comparison of ten machine learning models

16 - The best performed model at building and stock level are polynomial kernel

17 support vector regression and Gaussian radial basis function kernel support vector

18 regression respectively 


\section{Abstract}

23 The building sector accounts for $30 \%$ of final energy consumption and $28 \%$ of global
- Machine learning model applicable to building stock energy prediction and retrofit energy saving potential evaluation large share of total buildings' energy consumption. Building stock modelling for space heating and cooling energy prediction provides critical insights on the stock energy consumption and aid the building retrofit policy-making process with the evaluation of the energy-saving potential. By combining the physical modelling approach and datadriven approach, a hybrid approach is applicable for modelling the heating and cooling energy consumption of the building stock, including both residential buildings and nonresidential buildings. Within this framework, the Urban Modelling Interface (UMI) tool has been used for physical modelling to generate heating and cooling energy use intensity. Then, ten different machine learning models, including Gaussian radial basis function kernel support vector regression, linear kernel support vector regression, polynomial kernel support vector regression, random forests, extreme gradient boosting, ordinary least-squares linear regression, ridge regression, least absolute shrinkage, and selection operator, elastic net and artificial neural network, have been applied to predict heating and cooling energy use intensity (EUI). The approach has been demonstrated using a case study in Chongqing, China. The results show that machine learning models 
can achieve accurate building heating and cooling EUI prediction, with the polynomial kernel support vector regression showing the best accuracy at the level of a single building, and the Gaussian radial basis function kernel support vector regression performing the best at the stock level. Machine learning models generated by proposed hybrid approach not only provide quickly prediction of building space heating and cooling energy consumption at the stock level, but also support building retrofit decision makings by evaluate energy saving potential of various retrofit options.

Keywords: Building energy consumption; Heating and cooling; Building Stock modelling; Hybrid approach; Machine learning

\section{Introduction}

Buildings are responsible for $30 \%$ of final energy consumption and $28 \%$ of global energy-related carbon dioxide emissions in 2018 according to the International Energy Agency [1]. Building energy conservation and carbon emission reduction are actively promoted by governmental authorities by leveraging on legislation and policies, such as the Energy Performance of Buildings Directive and the Energy Efficiency Directive in the EU [2] and the 13th Five Year Plan in China [3].

Space heating and cooling through mechanical systems are the primary active methods to adjust the building indoor thermal conditions but at the expense of a significant amount of energy. As examples, in residential buildings the space heating and cooling account for $58 \%$ and $41 \%$ of urban and rural household energy consumption in China 

consumption in the United Kingdom [6] and 65\% of the household energy consumption in the European Union [7]. In non- residential buildings, the space heating and cooling account for $34 \%$ of commercial building energy consumption in the United States [8],

$6450 \%-60 \%$ of public building energy consumption in China [9], and $45 \%$ of nondomestic premises energy consumption across England and Wales [10]. The high energy demand for space heating and cooling thus entails massive building energy conservation and carbon emissions reduction potential if tailored building retrofit measures are undertaken.

To understand the building stock energy consumption and study various building retrofit measures, building stock energy modelling - a successor of building energy

71 modelling - is utilized to expand the study area to a larger scale and offers architects, urban planners, and policymakers a valid decision support tool [11]. Modelling the space heating and cooling energy consumption boosts policy-making process by providing critical insights on the building stock built environment control-related energy consumption; further, it proves particularly useful to areas in which building energy consumption statistics is lacking, or detailed building end-use split for space heating and cooling is not available. Moreover, the space heating and cooling energy consumption model is also capable of evaluating the energy conservation potential of various building retrofit measures at the stock level and help with the selection of the best performing measures. 
This study deployed a hybrid approach to generate data-driven energy prediction model for large-scale building stock covering both residential building and non-residential building without existing building energy consumption data. The structure of the paper is as following: Section 2 includes the related literatures as well as the aims and objectives of this study. Section 3 presents the methodology applied in this study, which use hybrid approach to predict building space heating and cooling energy consumption.

Follows by Section 4 demonstrates the proposed hybrid approach using a case study in Chongqing, China. The discussions and conclusions of the study are covered in Section 5 and Section 6 respectively.

\section{Literature review}

\subsection{Data-driven building energy consumption prediction}

The data-driven building energy consumption prediction has been gaining raising research interest in recent years [12]: it has been widely used to predict building energy consumption of buildings with different functions, such as residential [13-22], office [23-29], institutional [30, 31], educational [32, 33] and commercial [34]. However, the application of the data-driven approach in large scale building stock energy consumption prediction is rather limited [34-36], this might because the majority of existing research about data-driven building energy consumption prediction is focused on residential or non-residential buildings only [12], although building stock usually consists of a mix of both types of building. Build up a data-driven energy consumption 

extending the application of data-driven approach in large scale building stock.

To the best of our knowledge, there are only a few data-driven building energy consumption prediction studies considering both residential and non-residential

105 buildings, such as that of Georgescu, et al. [37] who studied offices, laboratories, 106 gymnasiums, dormitories, and restaurants. Instead of creating one model able to predict 107 both the residential and non-residential building's energy demand, they generated an 108 individual support vector machine model for building energy consumption data from 109 every building utility meters. Kontokosta and Tull [38] applied linear regression, 110 random forest, and support vector regression algorithms to predict the energy use of 1.1 111 million buildings in New York City of various functions, the building energy usage data 112 used to train the model came from Local Law 84 energy disclosure data. Hawkins, et 113 al. [39] used the artificial neural network to estimate the energy use in UK university 114 campus buildings, such as dormitories, laboratories, and offices, by using Display 115 Energy Certificate (DEC) to develop artificial neural network energy prediction model.

116 Robinson, et al. [40] developed 11 different machine learning models using the 117 Commercial Buildings Energy Consumption Survey (CBECS) data to estimate 118 commercial building energy consumption. The commercial buildings have been studied 119 including both commercial buildings for a residential purpose like lodging building and 120 commercial buildings for non-residential purpose like the office building. Similarly, 121 Cheng [41] also based on the CBECS data to build 10 machine learning models for 
122

123 Chicago has been used for model validation. Abbasabadi, et al. [42] demonstrated an

124 integrated data-driven framework for urban energy use modelling taking Chicago as a

125 case study. They tested multiple linear regression, nonlinear regression, classification

126 and regression trees, random decision forest, k-nearest neighbours and artificial neural

127 intelligence for operational energy use prediction considering both residential and non-

128 residential buildings. The building energy data used is obtained by merging the Chicago

129 energy benchmark and Chicago energy usage datasets. Pan and Zhang [43] employed

130 categorical boosting model, random forest and gradient boosting decision tree in

131 estimate energy consumption of non-residential and multifamily building, Seattle's

132 building energy performance data collected by Seattle's Energy Benchmarking Program

133 is used as main dataset. However, the rich building energy consumption datasets, like

134 Local Law 84 energy disclosure data, DEC data, CBECS data, Chicago energy

135 benchmark dataset and Seattle's building energy performance data, are currently

136 available only for a limited number of cities and countries. The lack of building energy

137 consumption datasets [44], needed as a training set, impede the use of a data-driven

138 approach in the large scale building stock [45].

\subsection{Hybrid approach in building stock energy modelling}

140 Top-down and bottom-up methods are generally used to develop building stock models

141 [46-48]. Top-down methods have embedded the main limitation of lack of technical

142 detail specifications and are unable to determine the energy consumption of each end- 
143

144

145

146

147

148

150

151

152

153

154

155

156

157 the measured energy data in U.S. homes as a part of statistical post-processing

158 techniques. Similarly, Brøgger, et al. [52], [53] adopted a hybrid approach by using

159 multiple linear regression to calibrate a physical model of the Danish residential

160 building stock. Li and Yao [54] compared the performance of linear regression, artificial

161 neural network and support vector regression in predicting the residential annual space

162 heating and cooling loads. The annual residential heating and cooling load intensity

163 database utilized in machine learning models' training and validation process is 

generated a building energy database representative of non-residential Italian building stocks. Based on the database, multiple linear regression models are develop to predict

168 building heating, cooling and comprehensive energy demand. Luo, et al. [56] proposes

169 a multi-objective prediction framework for building heating, cooling, lighting loads and

170 BIPV electrical power production. By using building operating and energy data

171 generated by TRNSYS simulation of a general office building, artificial neural network, 172 support vector regression and long-short-term-memory neural network based predictive 173 models are trained and tested. Although adapted a hybrid approach, the aforementioned

174 five studies focus on the residential building or non-residential building only. Goel, et 175 al. [57] build random forest regression models based on building stock simulations for 176 buildings energy efficiency prediction in developing the Asset Score Preview tool, a 177 rating system tool. In their research, 22 building types embedding both commercial 178 buildings and mid- to high-rise residential buildings were studied with one regression 179 model generated per every building type. There is a lack of study using hybrid approach 180 for energy modelling of both residential building and non-residential building to enable 181 large-scale building stock energy prediction.

\subsection{Aims and objectives}

183 To extend the application of data-driven model to large-scale building stock and to 184 alleviate the challenges of commonly unavailable building energy consumption data to 
support model generation, a hybrid approach has been employed to develop a dataprediction approach, the prediction accuracy of ten different machine leaning models is also compared based on the case study.

\section{Methodology}

191 The proposal of a new hybrid approach for building energy stock modelling consists of

1925 steps, including the heating and cooling energy consumption estimation, machine

193 learning models, model generation process, model performance evaluation as well as

194 the application of selected machine learning model (see Figure 1).

195 Step 1: Based on building information collected through a field survey and related

196 building characteristics settings, Urban Modeling Interface (UMI) was used to simulate

197 the space heating and cooling energy consumption of all single-use buildings within the 198 study stock.

199 Step 2: Suitable machine learning models for predicting building space heating and 200 cooling energy use intensity (EUI) at the individual building level have been 201 investigated.

202 Step 3: Generation of the machine learning models through pre-process of the raw 203 dataset; train with the training and validation set, and test models by apply them to 204 predict the EUIs of the testing set buildings. 
205 Step 4: Evaluate the prediction accuracy of the machine learning models at both 206 individual building and stock levels to compare the machine models' performance when 207 considering both residential and non-residential buildings.

208 Step 5: Based on the further analysis scope, prioritize building level accuracy or stock 209 level accuracy to select the best performed model. The selected machine learning model 210 can be applied to building space heating and cooling energy consumption prediction, 211 as well as building retrofit space heating and cooling energy saving potential evaluation. 


\section{The application of hybrid approach in building stock modelling}

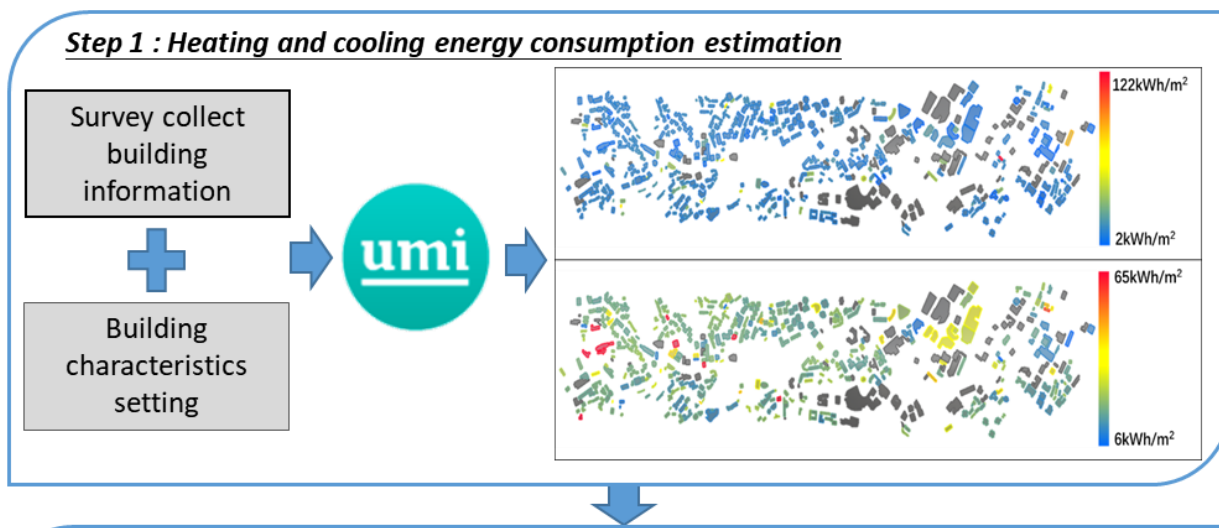

Step 2 : Machine learning models

Support vector regression (SVR)

$>$ Gaussian radial basis function kernel SVR

$>$ Linear kernel SVR

Polynomial kernel SVR

Linear models

$>$ Ordinary least-squares linear regression

$>$ Ridge regression

$>$ Least absolute shrinkage and selection operator

Random forests

Elastic net

Extreme gradient boosting

Artificial neural network

Step 3 : Model generation process

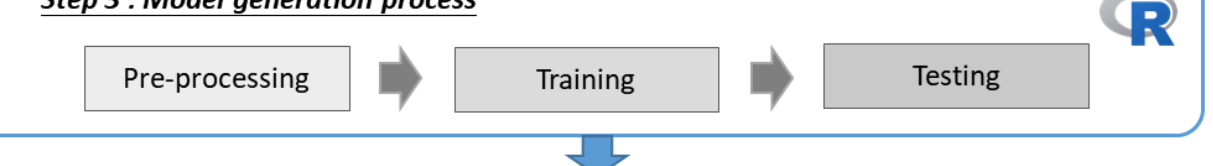

Step 4 : Model performance evaluation

Building level

-Relative error

- Normalised mean absolute error

-Normalised root-mean-square error

Stock level

-Relative error

Step 5 : The application of selected machine learning mode

Building space heating and cooling energy consumption prediction

Building retrofit space heating and cooling energy saving potential evaluation

213 Figure 1: Framework of the research

214 The detail implication of those five steps is described in the following sections 3.1 to 2153.5.

217 As stated above, the rich building energy consumption datasets are not commonly

218 available, so the building energy consumption information needed for data-driven 
model development is estimated by using physical models. In this study, the energy consumption of every studied building is simulated individually by using Urban

221 Modeling Interface (UMI) [58], a modelling software package that utilizes EnergyPlus

222 [59] as the simulation core engine. UMI can simulate space heating and cooling energy

223 use intensity (EUI) for individual buildings at the urban scale in a fast but accurate

224 manner by using a 'shoeboxer' algorithm [60], which makes it a handy physical

225 modelling tool to handle a relatively small scale buildings stock. UMI needs 3D

226 building model of the stock, together with all detailed building characteristics required

227 by EnergyPlus, such as the building envelope thermal physical characteristics and

228 HVAC system, at individual building level to simulate building heating and cooling

229 energy consumption. As detailed building characteristics are essential for UMI

230 simulation, the UMI simulation setting and running process are both labour intensive

231 and time-consuming [61], which does limit its applicability to the large scale building 232 stock.

233 The heating and cooling energy consumption results from UMI simulation is combined

234 with the building detailed characteristics to create the machine learning database. The

235 database is divided into two subsets and utilised in two ways: 1) as training and

236 validation set to train machine learning models; 2) as testing set to test the performance

237 of machine learning models and compare their accuracy with UMI simulation. 


\subsection{Machine learning models}

239 Five classes of machine learning technique are investigated in this study to predicting

240 space heating and cooling energy consumption, including support vector regression,

241 random forest, extreme gradient boosting, linear model and artificial neural network.

242 Ten different machine learning models are built based on the machine learning database

243 generated in the previous step.

244 3.2.1. Support vector machine

245 Commonly recognized as the best supervised learning algorithms in solving regression,

246 problems [62], SVMs are increasingly used in building energy analysis [63].

247 Introduced by Cortes and Vapnik [64] in 1995, the support vector machine (SVM) was

248 initially developed in the context of classification. Based on structural risk

249 minimization inductive principle, SVM aims at minimizing the generalization error

250 through reducing a summation of empirical risk and a Vapnik Chervonenkis (VC)

251 dimension term, which generally leads to higher generalization performance in solving

252 nonlinear problems [62]. Support vector regression (SVR), as an extension of the

253 support vector classification (SVC), provides a quantitative response to the input

254 predictor variables [65]. It seeks coefficients to minimise the effect of outliers on the

255 regression equations; however, only residuals larger in absolute value than some

256 positive constant $(\varepsilon)$ are considered in the loss function [65, 66]. $\varepsilon$-insensitive loss

257 functions (equation 1) were used to construct the SVR model and ensure robust and 
sparse estimation. Only when the discrepancy between the SVR model predicted

259 building EUI and simulated building EUI is higher than $\varepsilon$, the absolute difference will

260 contribute to the loss.

261

$L(\mathrm{y}-\mathrm{f}(\mathrm{x}))=\left\{\begin{array}{c}0, \text { if }|\mathrm{y}-\mathrm{f}(\mathrm{x})| \leq \varepsilon \\ |\mathrm{y}-\mathrm{f}(\mathrm{x})|-\varepsilon, \text { otherwise }\end{array}\right.$

262 In the case of linear functions $\mathrm{f}(x)=\langle w, x\rangle+b$ with $w \in \mathrm{X}, \mathrm{b} \in P(\langle; \cdot\rangle$ denotes the

263 dot product in $\mathrm{X})$, given training data $\left\{\left(x_{1}, y_{1}\right), \ldots,\left(x_{n}, y_{n}\right)\right\} \subset X \times P$. The goal of SVR

264 is to find a function $\mathrm{f}(x)$ that has at most $\varepsilon$ deviation from the obtained targets for all

265 the training data, and at the same time is as flat as possible. Slack variables $\xi_{i}$ and $\xi_{i}^{*}$

266 are introduced to guard against outliers and to adopt the soft-margin approach, in case

267 the convex optimization problem is not always feasible. The optimization problem is

268 presented in equation 2 [67].

269 minimize $\frac{1}{2}\|w\|^{2}+C \sum_{i=1}^{n}\left(\xi_{i}+\xi_{i}^{*}\right)$

$270 \quad$ subject to $\left\{\begin{array}{c}y_{i}-\langle w, x\rangle-b \leq \varepsilon+\xi_{i} \\ \langle w, x\rangle+b-y_{i} \leq \varepsilon+\xi_{i}^{*} \\ \xi_{i}, \xi_{i}^{*} \geq 0\end{array}\right.$

$271 \mathrm{C}$ is a positive constant that measures the trade-off between the flatness of function

$272 \mathrm{f}(x)$ and the amount up to which deviations larger than $\varepsilon$ are tolerated.

273 The abovementioned optimization problem can be solved by constructing a Lagrange

274 function, the function $\mathrm{f}(x)$ can be derived as equation 3 [67],

$275 f(x)=\sum_{i=1}^{n}\left(\alpha_{i}-\alpha_{i}^{*}\right)\left\langle x_{i}, x\right\rangle+b$

276 Where, $\alpha, \alpha^{*}$ are Lagrange multipliers of non-negative real numbers. 
277 In the case of nonlinear functions, as the relationship between the building

278 heating/cooling EUI and the selected predictor variables, the predictor variables need 279 to be pre-processed and map from input space into feature space. The function $\mathrm{f}(x)$ is 280 written as equation 4 [67]:

$281 \quad f(x)=\sum_{i=1}^{n}\left(\alpha_{i}-\alpha_{i}^{*}\right) k\left(x_{i}, x\right)+b(4)$

282 Three different kernel functions $k\left\langle x_{i}, x\right\rangle$ is used to generate three different SVR 283 models, including Linear kernel(equation 5) for Linear kernel SVR, Polynomial kernel 284 (equation 6) for polynomial kernel SVR and Gaussian radial basis function kernel 285 (equation 7) for Gaussian radial basis function kernel SVR [68].

$286 k\left(x_{i}, x\right)=x_{i} \cdot x(5)$

$287 k\left(x_{i}, x\right)=\left(\text { scale } \cdot x_{i} \cdot x+\text { offset }\right)^{\text {degree }}$

$288 k\left(x_{i}, x\right)=\exp \left(-\sigma\left\|x_{i}-x\right\|^{2}\right)$

290 Random forests is an ensemble learning approach to supervised learning [69], it can be

291 used for both classification and regression. Thanks to the advantage of fast training 292 speed [70], random forests becomes one of the most widely used machine learning 293 techniques [71]. The random forest for regression is formed by growing trees 294 depending on a random vector such that the tree predictor takes on numerical values by 295 average the prediction of every tree [72]. The algorithm for random forest regression is 
1. For $\mathrm{b}=1$ to $B$ :

(a) Draw a bootstrap sample $\mathbf{Z}^{*}$ of size $N$ from the training data.

(b) Grow a random forest tree $T_{b}$ to the bootstrapped data, by recursively repeating the following steps for each terminal node of the tree, until the minimum node size $S_{\text {min }}$ is reached.

i. $\quad$ Select $m$ variables at random from the $p$ variables.

ii. Pick the best variables/split-point among the $m$ variables.

iii. Split the node into two daughter nodes.

2. Output the ensemble of trees $\left\{T_{b}\right\}_{1}^{B}$.

To make a prediction at a new point $x$ :

$\hat{f}_{r f}^{B}(x)=\frac{\sum_{b=1}^{B} T_{b}(x)}{B}$

297 Where B is the number of trees.

298 3.2.3. Extreme gradient boosting

299 Extreme gradient boosting, commonly referred to as XGBoost, is a scalable machine

300 learning system for tree boosting [74]. As one of the boosting models, extreme gradient

301 boosting grow trees sequentially. Starting from building the first tree based on the

302 training data, then a second tree is created to correct the errors from the first tree. More

303 trees are added until the model can predict the training set perfectly or the number of

304 trees reaches the upper limit. Extreme gradient boosting is 'an optimized distributed

305 gradient boosting library designed to be highly efficient, flexible and portable' [75],

306 and can be used to handle regression, classification, and ranking problems [76].

307 Extreme gradient boosting achieved state-of-the-art results in machine learning

308 competitions [77], and was proved to outperform other ten machine learning models at

309 commercial building energy consumption prediction [40]. 
310 Based on data set with $\mathrm{n}$ examples and $\mathrm{m}$ features $\mathrm{D}=\left\{\left(X_{i}, y_{i}\right)\right\}\left(|\mathrm{D}|=\mathrm{n}, X_{i} \in \mathrm{P}^{\mathrm{m}}, y_{i} \in\right.$

311 P), extreme gradient boosting predicts output by using $\mathrm{K}$ additive functions, as shown 312 in equation 8 [74].

$313 \widehat{y}_{l}=\varnothing\left(X_{i}\right)=\sum_{k=1}^{K} f_{k}\left(X_{i}\right), f_{k} \in \Phi,(8)$

314 Each $f_{k}$ corresponds to an independent tree structure, $\Phi$ is the space of regression trees.

315 The regularized objective function presented in equation 9 is optimized in extreme 316 gradient boosting to learn the set of functions [74],

$317 \Lambda(\varnothing)=\sum_{i} l\left(\widehat{y}_{l}, y_{i}\right)+\sum_{k} \Omega\left(f_{k}\right)(9)$

318 where $\Omega(f)=\gamma T+\frac{1}{2} \lambda\|\omega\|^{2}$

$319 l$ is a differentiable convex loss function that measures the difference between the 320 prediction $\widehat{y}_{l}$ and the target $y_{i}$, while $\Omega$ is model complexity penalization term. $\mathrm{T}$ is 321 the number of leaves in the tree, $\omega$ is the leaf weights.

322 The more detailed mathematical implication of extreme gradient boosting can be found 323 in Chen and Guestrin [74] and Chen and He [78].

324 3.2.4. Linear models

325 For linear models, the relationship between the predicted variable and predictors can 326 directly or indirectly be written according to the following equation 10 [66]. They are 327 selected for their simplicity, intuitive and ability to provide a baseline performance 328 measure $[55,79]$. 
$y_{i}=b_{0}+b_{1} x_{i 1}+b_{2} x_{i 2}+\cdots+b_{j} x_{i j}+e_{i}(10)$

330 where $y_{i}$ is the numeric response for the $\mathrm{i}^{\text {th }}$ sample; $b_{0}$ is the estimated intercept; $b_{j}$

331 is the estimated coefficient for the $\mathrm{j}^{\text {th }}$ predictor variable; $x_{i j}$ is the value of the $\mathrm{j}^{\text {th }}$

332 predictor variable for the $\mathrm{i}^{\text {th }}$ sample; and $e_{i}$ is the random error of the linear regression

333 model.

334 For ordinary least-squares linear regression, the aim is to minimise the sum-of-squared

335 errors ( $\mathrm{SSE}_{\mathrm{ols}}$, shown in equation 11) between the observed value and model-predicted

336 value [66].

$337 \quad \mathrm{SSE}_{\text {ols }}=\sum_{i=1}^{n}\left(y_{i}-\widehat{y}_{l}\right)^{2}$

338 The $y_{i}$ and $\widehat{y}_{\imath}$ are the observed value and model-predicted value of the $\mathrm{i}^{\text {th }}$ sample.

339 In ridge regression, to pursue smaller mean squared error, a biased model is generated

340 by adding a penalty to the $\mathrm{SSE}_{\mathrm{rr}}[80]$ as shown in equation 12 :

$341 \quad \mathrm{SSE}_{r r}=\sum_{i=1}^{n}\left(y_{i}-\widehat{y}_{l}\right)^{2}+\lambda \sum_{i=1}^{n} b_{j}^{2}(12)$

342 For the least absolute shrinkage and selection operator model [81], as the

$343 \mathrm{SSE}_{\text {lasso }}$ (shown in equation 13) is penalized by the absolute values, the penalty value $\lambda$

344 can reach 0 , so the lasso model also conducts feature selection.

$345 \operatorname{SSE}_{\text {lasso }}=\sum_{i=1}^{n}\left(y_{i}-\widehat{y}_{l}\right)^{2}+\lambda \sum_{i=1}^{n}\left|b_{j}\right|$

346 The elastic net model combined two types of penalties to enable effective regularization

347 via the ridge-type penalty with the feature selection quality of the lasso penalty[66]. 
The $\mathrm{SSE}_{\mathrm{en}}$ is presented in the following equation 14 [82]:

3.2.5. Artificial neural network

351 With the benefits of high speed, high accuracy, and capability of handling nonlinear 352 relationships between variables [83], artificial neural network is the most widely 353 applied artificial intelligence models in the building energy prediction [63]. It mimics 354 how the brain responds to stimuli from sensory inputs to interpret the relationship 355 between input and output signals [84]. The neuron is the information-processing unit 356 of the neural network, the mathematical description of a neuron is shown in equation 35715 [85]:

$y_{k}=\varphi\left(\sum_{j=1}^{m} w_{k j} x_{j}+b_{k}\right)$

359 where, $x_{1}, x_{2}, \ldots x_{m}$ are the input signals; $w_{k 1}, w_{k 2}, \ldots w_{k m}$ are the synaptic weights of

360 neuron $\mathrm{k} ; b_{k}$ is the bias; $\varphi(\cdot)$ is the activation function; and $y_{k}$ is the output signal 361 of the neuron.

\subsection{Model generation process}

363 Machine learning models are generated via the process presented in Figure 2. All

364 predictor variables are centred and scaled as pre-process before model training to avoid 365 domination from attributes in higher numeric range and improve numerical stability $366[24,66]$. After the pre-processing, all the available data are randomly divided into two 
parts, with $25 \%$ as the testing set and $75 \%$ as the training and validation set (the

370 all data in the training and validation set is further partitioned into ten equally sized

371 subsets and undergo the 10-fold cross-validation process. By repeating the process of

372 using nine subsets as a training set and one subset as the validation set for 10 times, the

373 tuning parameter(s) of the machine learning models are determined as the one(s) with

374 the best average performance for the 10 different validation sets. Then, the final model

375 is generated using all data from the training and validation set and the untouched testing

376 set is used to evaluate the prediction accuracy of the models.

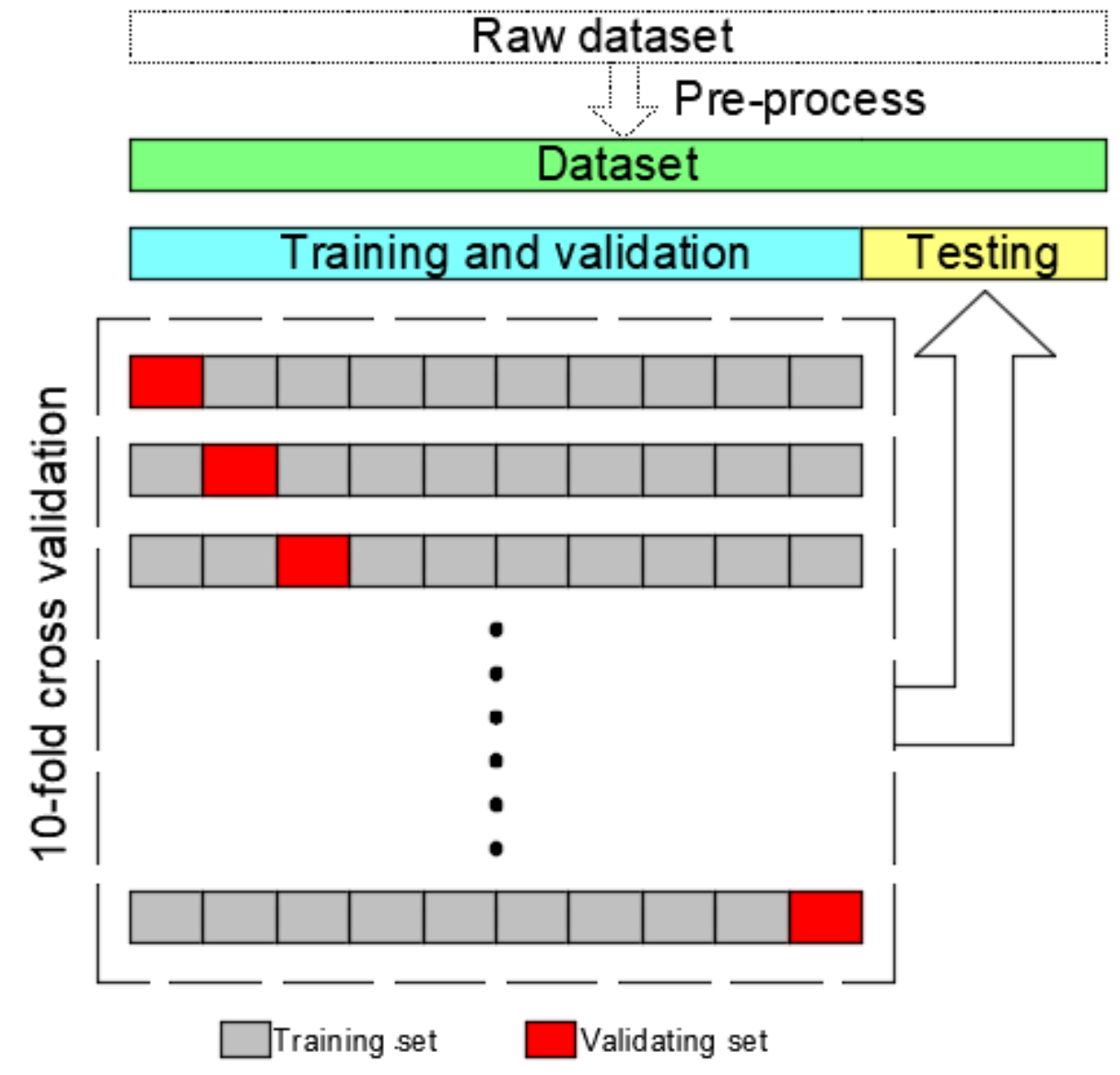

Figure 2: Machine learning model generation process 
380 All buildings in the testing set are used to evaluate the performance of the machine

381 learning model in predicting EUI as an unseen dataset. The accuracy of the machine

382 learning-based model on individual building heating and cooling EUI prediction is

383 investigated using relative error as per equation 16 :

$384 \quad \delta_{k}=\frac{\widehat{y_{k}}-y_{k}}{y_{k}} \times 100 \%(16)$

385 Here $\delta_{k}$ is the relative error of using 'machine learning'-based model to predict

386 heating/cooling EUI of building $\mathrm{k}$ against UMI simulations;

$387 y_{k}$ is the building heating/cooling EUI for building $\mathrm{k}$ from the UMI simulation 388 generated database;

$389 \widehat{y_{k}}$ is the predicted building heating/cooling EUI for building $\mathrm{k}$ from the machine 390 learning model;

391 The average prediction performance of different machine learning models at the

392 individual building level is indicted by normalised mean absolute error (NMAE) and

393 normalised root-mean-square error (NRMSE) for heating and cooling EUI. Their

394 calculation formulas are presented in equations 17-18.

$395 \quad$ NMAE $=\frac{\frac{\sum_{k=1}^{n}\left|y_{k}-\widehat{y_{k}}\right|}{n}}{\frac{\sum_{k=1}^{n} y_{k}}{n}}$

$396 \quad$ NRMSE $=\frac{\sqrt{\frac{\sum_{k=1}^{n}\left(y_{k}-\widehat{y_{k}}\right)^{2}}{n}}}{\frac{\sum_{k=1}^{n} y_{k}}{n}}$ 
397 Where $\mathrm{n}$ is the total number of buildings in the testing set.

398 To evaluate the accuracy of machine learning models on whole stock, residential stock

399 and non-residential stock level energy prediction, the relative error of gross heating and

400 cooling energy consumption of all buildings in the testing set, all residential buildings

401 in the testing set and all non-residential buildings in the testing set are estimated using

402 equation 19 respectively:

$403 \quad \delta_{\text {Stock }}=\frac{\sum_{k=1}^{m}\left(\widehat{y}_{k} \times F_{k}\right)-\sum_{k=1}^{m}\left(y_{k} \times F_{k}\right)}{\sum_{k=1}^{m}\left(y_{k} \times F_{k}\right)}$

404 Where, $\delta_{\text {Stock }}$ is the relative error of using machine learning based models to predict the

405 gross heating/cooling energy consumption of specific building stock in the testing set;

$406 \mathrm{~m}$ is the total number of buildings in the testing set belongs to the specific building

407 stock; $F_{k}$ is the total floor area of the building $\mathrm{k}$.

408 Apart from the prediction accuracy indexes described above, the running time to predict

409 the heating and cooling EUI of all buildings in the testing set is also tracked and 410 analysed.

411 3.5. The application of selected machine learning model

412 By comparing the prediction accuracy indexes of all ten machine learning models, the

413 best performed model can be selected based on the further analysis scope. If predicting

414 the space heating and cooling energy consumption precisely in the building level is

415 more important, then the building level accuracy indexes should be prioritize.

416 Otherwise, the best performed model should be select based on the stock level accuracy 
417 indexes. The selected machine leaning model is applicable to predict building space

418 heating and cooling energy consumption, evaluate energy saving potential for retrofit

419 measures as a substitute of building physical simulation.

\section{Case study}

421 The case study area is located in Yuzhong District of Chongqing city (China), covering

422 an area of about $3.4 \mathrm{~km}^{2}$ (see Figure 3). From July 2015 to September 2015, a field

423 survey was carried out to collect detailed building information for every building within

424 the study area; collected information included buildings' geographic location (longitude

425 and latitude), function, construction age, number of floors, window-to-wall ratio. For

426 construction age, instead of specific construction completed year, age band was

427 collected. Including three age bands for residential buildings (pre-2001, 2001-2010 and

428 post-2010) and four age bands for non-residential buildings (Pre-1990, 1990-2005,

429 2005-2015 and Post-2015). The construction age are collected for the building

430 construction information plaque and by asking the owners.

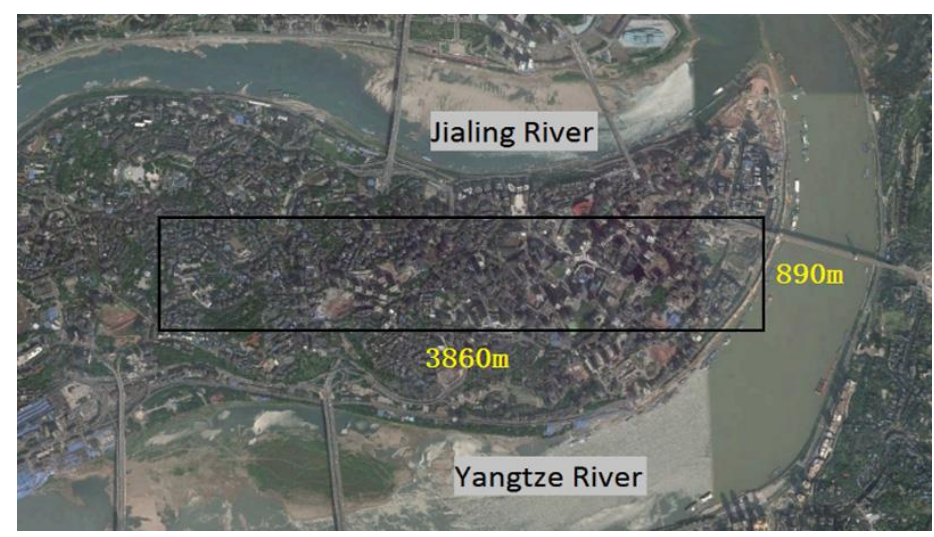

432 Figure 3: The case study area (highlighted by a black box) within the Yuzhong district 
The geographic location is used for locating buildings on online maps, then a building stock 3D model is generated by extrude the footprints by its height. The height of every building is calculated using the following equation 20 , while the window-to-wall ratio is set according to the filed survey.

Where $\mathrm{D}$ is the building height; $\mathrm{N}$ is the number of floors the building have; $\mathrm{d}$ is the average floor height, according to standards, it was set as three meters for residential buildings [89], four meters for offices [90], educational buildings [91, 92], hospitals [93] and hotels [94], five meters for malls [95].

\subsection{Characteristics of the buildings in the study area}

In total, there are 573 buildings located within the case study area. One hundred thirtyone of which are mixed-use multifunction building, while the rest of them are hosting residential buildings). The specific location of each building in the study area is shown

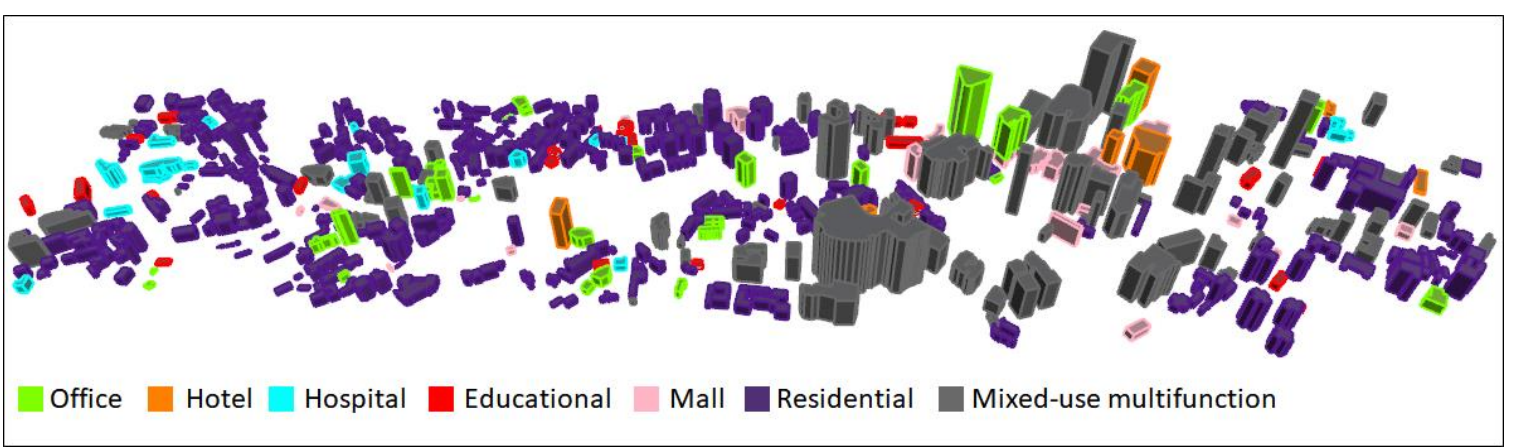

449 Figure 4: Building location and function 
450 The total number of single functions buildings is presented in Figure 5, including 334

451 residential buildings and 108 non-residential buildings. The residential building is

452 dominating the case study area as it accounted for more than three-quarters of all single-

453 function buildings. The construction age distribution of residential and non-residential

454 buildings is presented in Figure 6, majority of residential buildings are constructed 455 before 2001, while more than half of non-residential buildings are constructed during 4561990 to 2005.

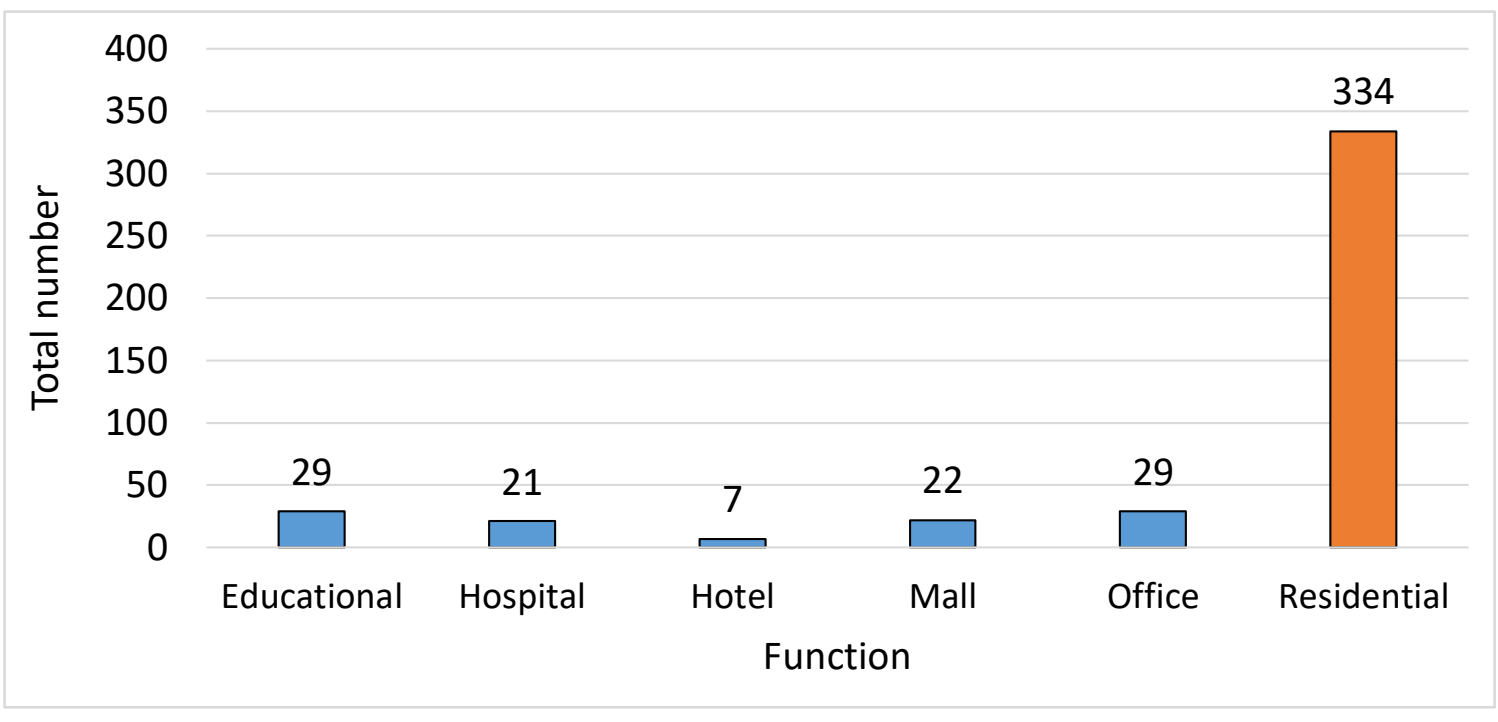

458 Figure 5: The total number of buildings with different functions 


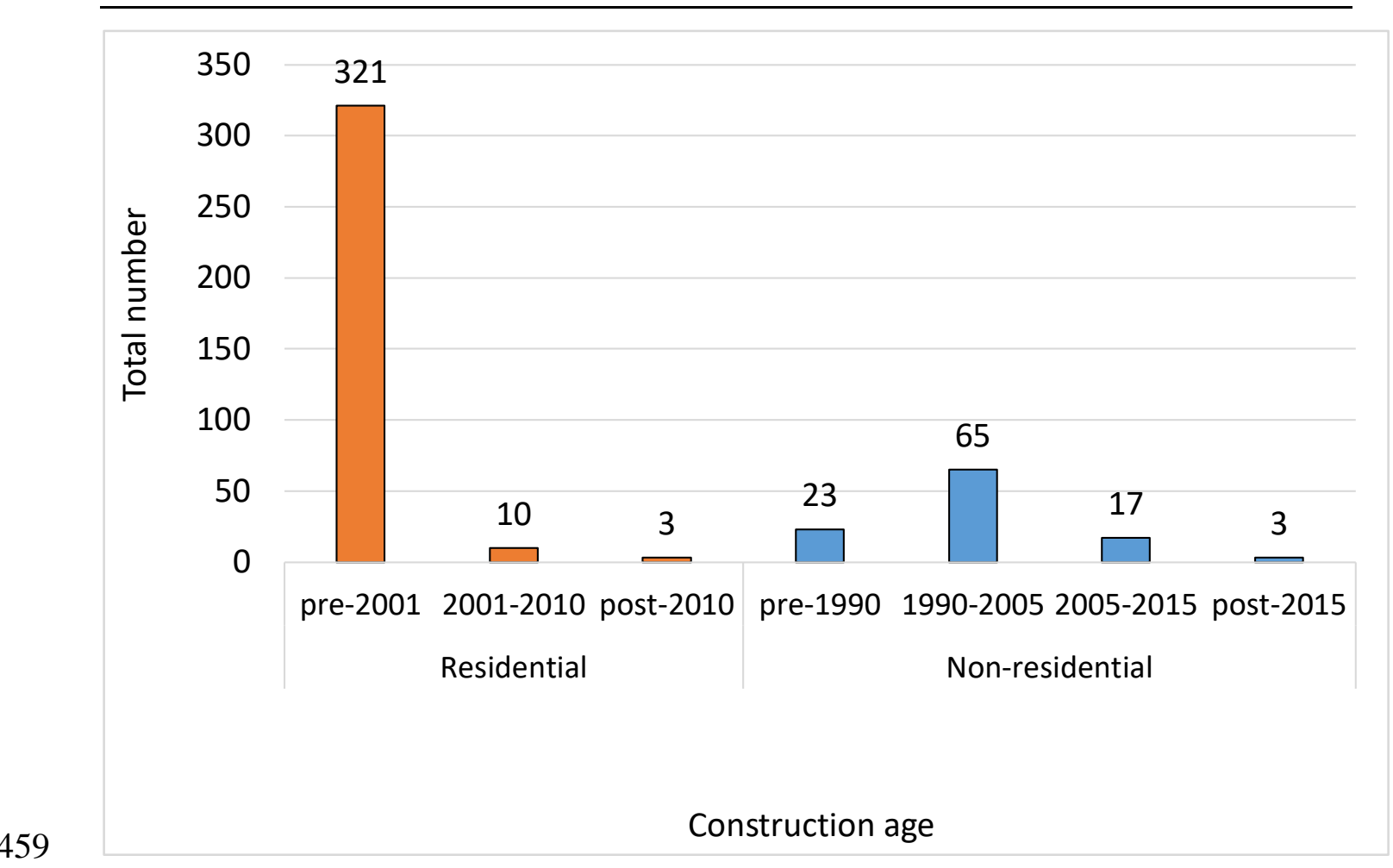

460 Figure 6: The construction age distribution of residential and non-residential buildings

461 In this study, only the 442 single function buildings are studied, due to the difficulty in 462 getting the real floor area function within mixed-use buildings.

463 The building's characteristics, including thermo-physical characteristics of the building 464 envelope, HVAC systems, and internal loads, are set according to the Chinese national 465 and industrial design standards based on the construction age of the buildings. JGJ 1344662001 [96], and JGJ 134-2010 [97] Standards are utilized to describe the building 467 characteristics of the residential building of different construction age. GBJ 19-1987 468 [98], GB 50189-2005 [99] and GB 50189-2015 [100] Standards are used to describe 469 the characteristics of non-residential buildings. The detailed building characteristics 470 setting for the residential and non-residential building is set according to Costanzo, et 471 al. [101], and are shown in Table 1. 
Table 1: Detailed building characteristics of non-residential and residential building [101]

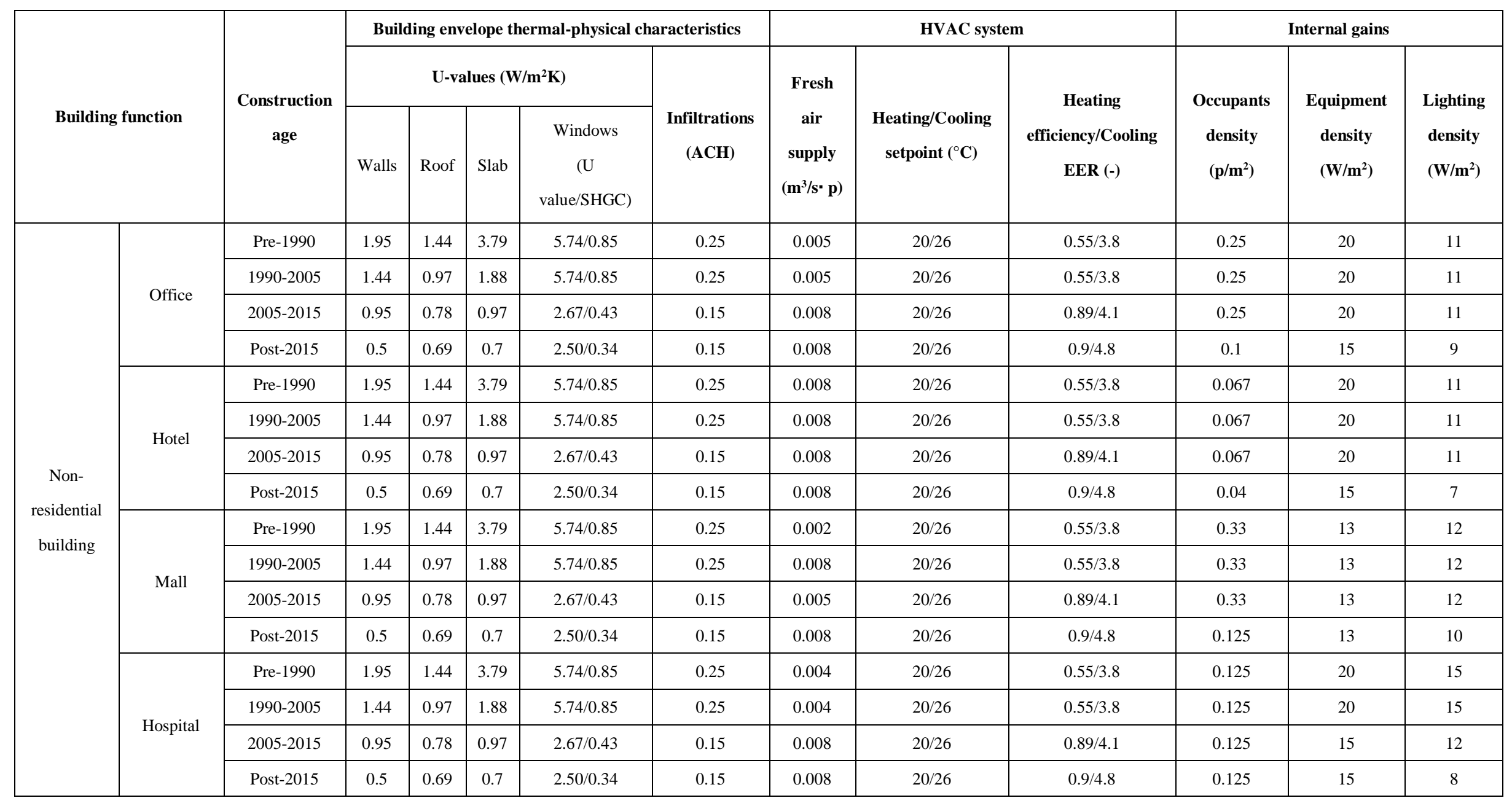




\begin{tabular}{|c|c|c|c|c|c|c|c|c|c|c|c|c|}
\hline \multirow{4}{*}{ Educational } & Pre-1990 & 1.95 & 1.44 & 3.79 & $5.74 / 0.85$ & 0.25 & 0.005 & $20 / 26$ & $0.55 / 3.8$ & 0.25 & 20 & 11 \\
\hline & 1990-2005 & 1.44 & 0.97 & 1.88 & $5.74 / 0.85$ & 0.25 & 0.005 & $20 / 26$ & $0.55 / 3.8$ & 0.25 & 20 & 11 \\
\hline & 2005-2015 & 0.95 & 0.78 & 0.97 & $2.67 / 0.43$ & 0.15 & 0.008 & $20 / 26$ & $0.89 / 4.1$ & 0.25 & 20 & 11 \\
\hline & Post-2015 & 0.5 & 0.69 & 0.7 & $2.50 / 0.34$ & 0.15 & 0.008 & $20 / 26$ & $0.9 / 4.8$ & 0.17 & 5 & 9 \\
\hline \multirow{3}{*}{ Residential building } & Pre-2001 & 1.97 & 1.62 & 3.74 & $5.74 / 0.85$ & 2 & 0 & $18 / 26$ & $1 / 2.2$ & 0.03 & 4.3 & 6 \\
\hline & 2001-2010 & 1.03 & 1 & 1.5 & $2.80 / 0.48$ & 1 & 0 & $18 / 26$ & $1.9 / 2.3$ & 0.03 & 4.3 & 6 \\
\hline & Post-2010 & 0.83 & 0.8 & 1.31 & $2.67 / 0.34$ & 1 & 0 & $18 / 26$ & $1.9 / 2.3$ & 0.03 & 4.3 & 6 \\
\hline
\end{tabular}


474 For non-residential buildings, the HVAC system is supposed to be in use for the whole 475 year, from 7 AM to 7 PM (12h) every weekday for office and educational buildings; 476 24h every day for hotel and hospital building; 8 AM-10 PM (14h) every day for the 477 mall. The HVAC system is available for the heating period (from December 1st to 478 February 28th) and cooling period (from June 15th to August 31st) only for residential 479 buildings. The daily residential HVAC usage is assumed based on the study of $\mathrm{Hu}$, et 480 al. [102], as an hour in the morning (from 7 AM-8 AM) and five hours when returning 481 home from work (from 6 PM-11 PM) for heating, as well as 6 PM-8 AM (14 hours) 482 and 1 PM-2 PM (1 hour) for cooling.

\subsection{Buildings'energy consumption}

484 The results of the UMI simulations are presented in Figure 7, heating and cooling EUIs 485 are available at the individual building level. As shown in Figure 8, heating EUI varies 486 from $2 \mathrm{kWh} / \mathrm{m}^{2}$ to $122 \mathrm{kWh} / \mathrm{m}^{2}$, while the cooling EUI varies from $6 \mathrm{kWh} / \mathrm{m}^{2}$ to 65 $487 \mathrm{kWh} / \mathrm{m}^{2}$ for all 442 single function buildings studied. The building energy consumption 488 data is combined with building detailed characteristics to create the database used to 489 develop machine learning models. 


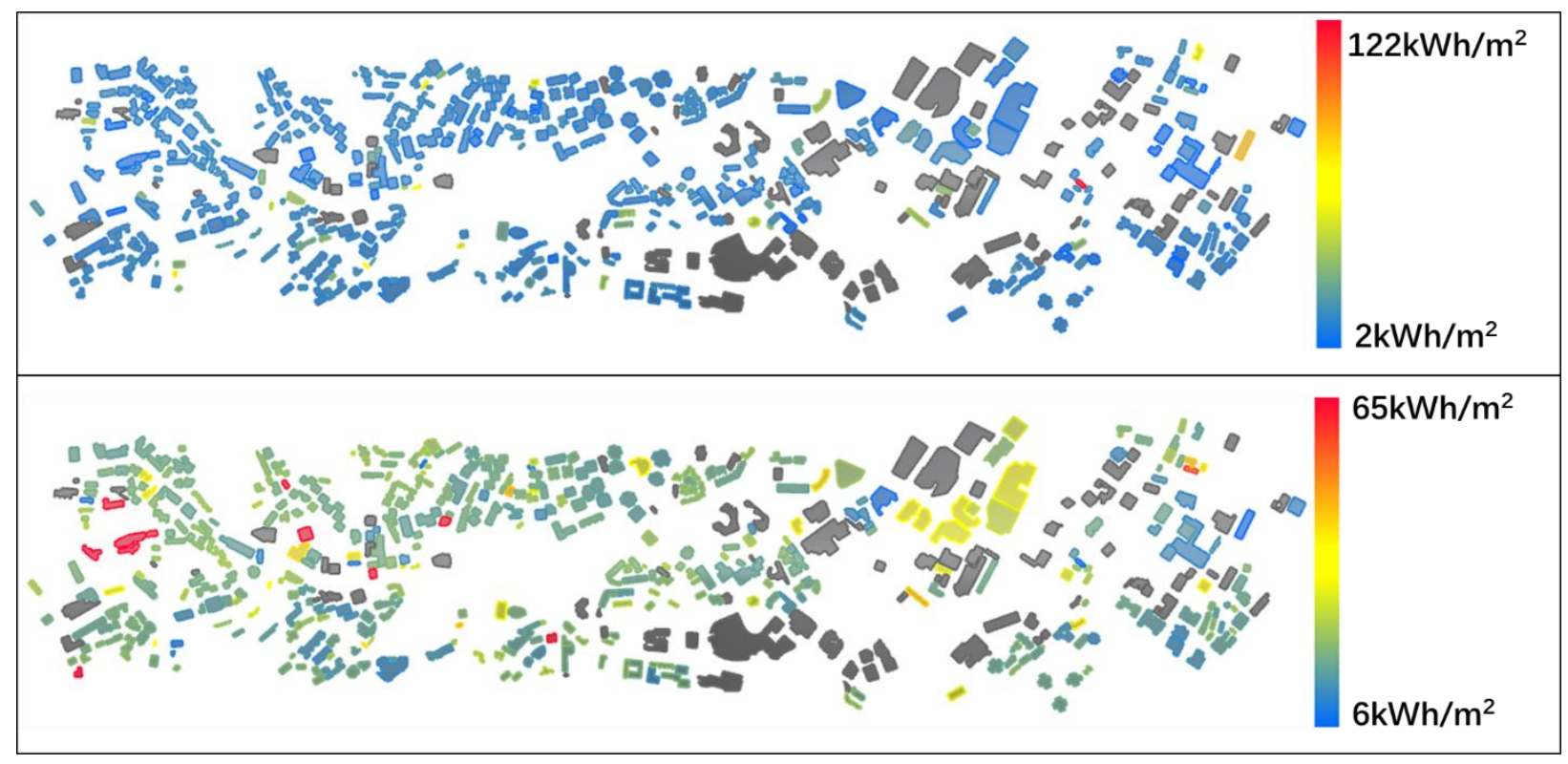

491 Figure 7: The heating (top) and cooling (bottom) EUI of buildings in the study area (the 492 buildings fill in grey are mixed-use buildings which are not simulated)

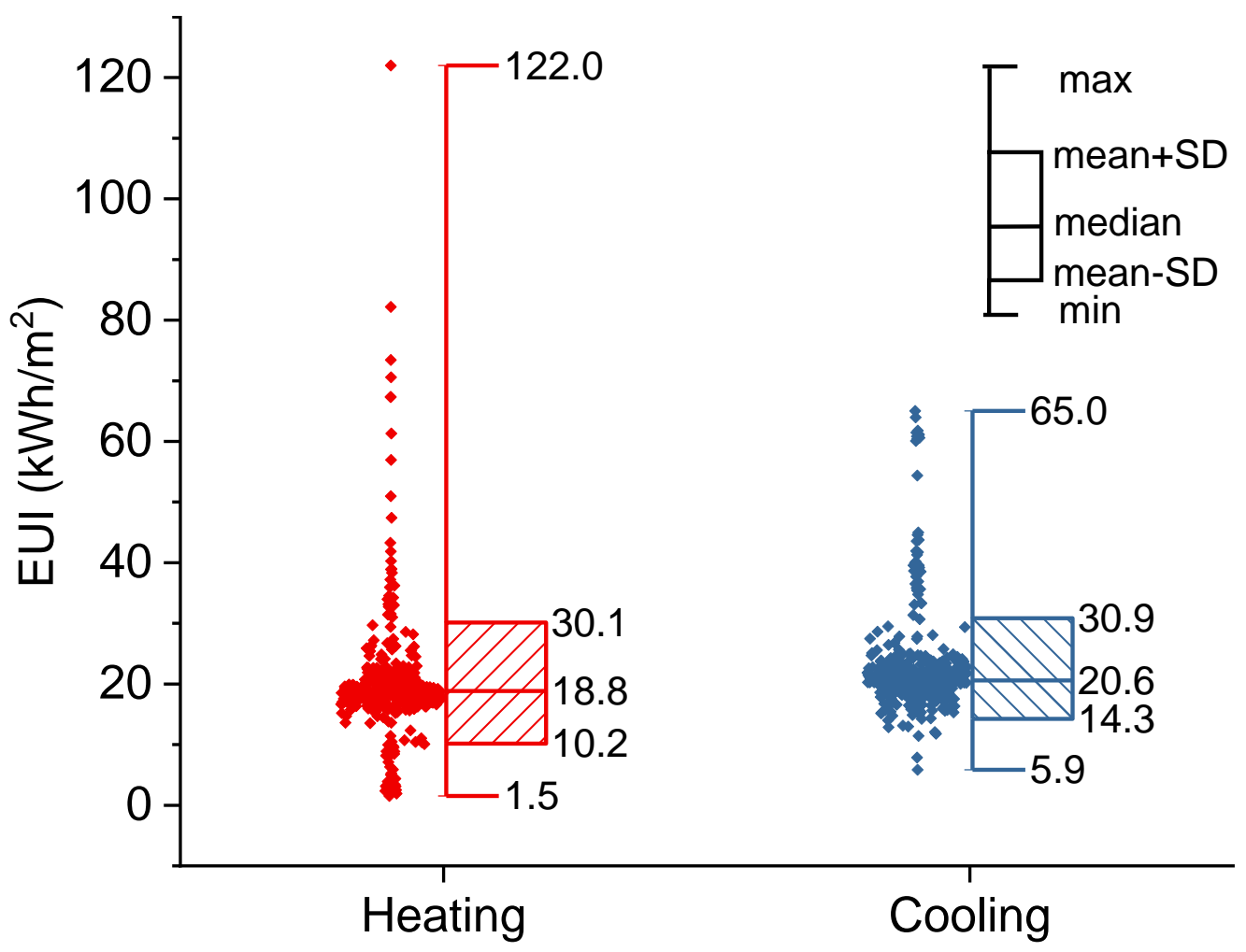

495 Figure 8: Boxplots of heating and cooling EUIs 
497 The building characteristics (listed in Table 2), including building geometry, building

498 envelope thermal-physical characteristics, building HVAC system and building internal

499 gains, are considered as main predictor variables as they are the main determinants for

500 building space heating and cooling energy consumption [103]. Predictor variables of

501 building geometry, building envelope thermo-physical characteristics, and building

502 internal gains are considered for both heating and cooling EUI prediction, while the

503 selection of predictor variables for building HVAC system is different. For heating EUI

504 prediction, only the fresh air supply, heating temperature setpoint, the heating

505 efficiency, and heating available proportion are considered, likewise, for cooling EUI

506 correlation analysis, only the fresh air supply, the cooling COP and cooling available

507 proportion are considered. The cooling setpoint is excluded from being a predictor

508 variable because of its constant value of $26^{\circ} \mathrm{C}$ for all buildings.

509 Table 2: Predictor variables for heating and cooling EUI prediction [orange shading 510 marks those used for heating EUI prediction only; blue shading marks those used for 511 cooling EUI prediction only; unshaded ones are used for both heating and cooling EUI 512 prediction] 


\begin{tabular}{|c|c|}
\hline Building characteristics & Predictor variables \\
\hline \multirow[t]{3}{*}{ Building geometry } & Building height $[\mathrm{m}]$ \\
\hline & Compactness ratio [/] \\
\hline & Window to wall ratio [/] \\
\hline \multirow{6}{*}{$\begin{array}{l}\text { Building envelope thermal- } \\
\text { physical characteristics }\end{array}$} & Walls U-value [W/m² $\mathrm{K}]$ \\
\hline & Roof U-value [W/m² $\mathrm{K}]$ \\
\hline & Slab U-value $\left[\mathrm{W} / \mathrm{m}^{2} \mathrm{~K}\right]$ \\
\hline & Windows U-value $\left[\mathrm{W} / \mathrm{m}^{2} \mathrm{~K}\right]$ \\
\hline & Windows solar heat gain coefficient (SHGC) [/] \\
\hline & Air infiltrations [ach] \\
\hline \multirow[t]{6}{*}{ Building HVAC system } & Fresh air supply $\left[\mathrm{m}^{3} / \mathrm{s} \cdot \mathrm{p}\right]$ \\
\hline & Heating setpoint $\left[{ }^{\circ} \mathrm{C}\right]$ \\
\hline & Heating efficiency [/] \\
\hline & HVAC available proportion for heating [/] \\
\hline & Cooling EER [/] \\
\hline & HVAC available proportion for cooling [/] \\
\hline \multirow[t]{3}{*}{ Building internal gains } & Occupants density $\left[\mathrm{p} / \mathrm{m}^{2}\right]$ \\
\hline & equipment density $\left[\mathrm{W} / \mathrm{m}^{2}\right]$ \\
\hline & Lighting density $\left[\mathrm{w} / \mathrm{m}^{2}\right]$ \\
\hline
\end{tabular}

513 The compactness ratio $(C R)$ is an index of building shape, and is calculated as per

514 following Equation 21 [61]:

$515 \quad \mathrm{CR}=\mathrm{S} / \mathrm{V} \quad(21)$

516 Where $\mathrm{S}$ is the surface area of the building;

$517 \mathrm{~V}$ is the enclosed volume of the building.

518 The HVAC available proportion (AP) for heating and cooling indicated the annual

519 portion of time when the HVAC system is available for heating and cooling respectively;

520 they are calculated using Equation 22:

$521 \quad \mathrm{AP}=\mathrm{H} / 8760(22)$

522 Where $\mathrm{H}$ is the total number of hours per annual when heating (or cooling) is available 
523 from the HVAC system.

524

525

526

527

528

531 the testing set can reasonably represent the prediction accuracy of applying those

532 machine learning models to other single-function buildings in Chongqing.

533 The relative error distribution of applying machine-learning models in heating and

534 cooling EUI for all buildings in the testing set is shown in Figure 9. The machine

535 learning models give an accurate prediction about building heating and cooling EUI.

536 The percentage of building within the $\pm 10 \%$ relative error varies between $61.8 \%$

537 (ordinary least-squares linear regression and least absolute shrinkage and selection

538 operator) to $85.5 \%$ (polynomial kernel support vector regression), and from $81.8 \%$

539 (linear kernel support vector regression) to $91.8 \%$ (Gaussian radial basis function kernel

540 support vector regression) for the heating and cooling cases, respectively. The

541 percentage of building within the $\pm 20 \%$ relative error varies between $80.0 \%$ (ridge

542 regression and elastic net) to $90.9 \%$ (polynomial kernel support vector regression) and 
544 regression) to $98.2 \%$ (artificial neural network) for heating and cooling.

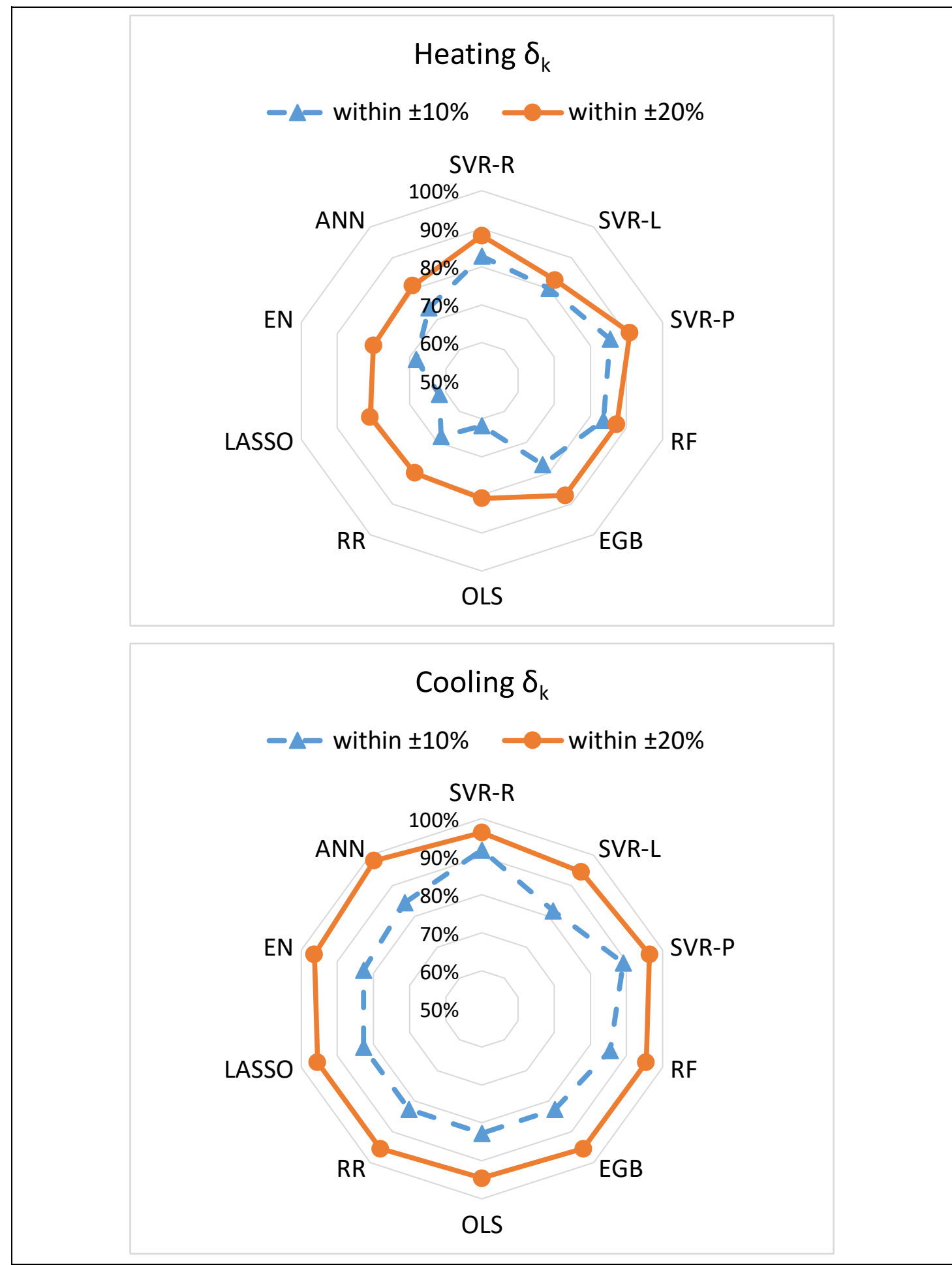

Figure 9: The relative error of the machine learning models in building heating (top) and cooling (bottom) EUI prediction (SVR-R: Gaussian radial basis function kernel support vector regression; SVR-L: linear kernel support vector regression; SVR-P: 
polynomial kernel support vector regression; RF: random forests; EGB: extreme gradient boosting; OLS: ordinary least-squares linear regression; RR: ridge regression; LASSO: least absolute shrinkage and selection operator; EN: elastic net; ANN: artificial neural network)

545 The NMAE and NRMSE of applying different machine learning models in the testing

546 set are presented in Table 3. In general, the prediction accuracy for cooling EUI is better

547 than heating EUI with smaller NMAE and NRMSE. For heating EUI prediction, the

548 NMAE varies from $7.3 \%$ (polynomial kernel SVR) to $17.2 \%$ (both ordinary least-

549 squares linear regression and least absolute shrinkage and selection operator model),

550 the NRMSE varies from $17.3 \%$ (polynomial kernel SVR) to $46.2 \%$ (extreme gradient

551 boosting). For cooling EUI prediction, the NMAE varies from 4.3\% (polynomial kernel

552 SVR) to $6.4 \%$ (both linear kernel SVR and elastic net), the NRMSE varies from $6.2 \%$

553 (polynomial kernel SVR) to $13.4 \%$ (extreme gradient boosting). The polynomial kernel

554 SVR has the best accuracy in the individual building level, followed by Gaussian radial

555 basis function kernel SVR.

556 Table 3: NMAE and NRMSE results of different machine learning models

\begin{tabular}{|l|c|c|c|c|}
\hline \multirow{2}{*}{ Machine learning models } & \multicolumn{2}{|c|}{ Heating EUI } & \multicolumn{2}{c|}{ Cooling EUI } \\
\cline { 2 - 5 } & NMAE & NRMSE & NMAE & NRMSE \\
\hline Gaussian radial basis function kernel SVR & $8.4 \%$ & $19.3 \%$ & $4.9 \%$ & $8.8 \%$ \\
\hline Linear kernel SVR & $11.2 \%$ & $23.9 \%$ & $6.4 \%$ & $10.9 \%$ \\
\hline Polynomial kernel SVR & $7.3 \%$ & $17.3 \%$ & $4.3 \%$ & $6.2 \%$ \\
\hline Random forests & $12.0 \%$ & $40.1 \%$ & $5.2 \%$ & $8.9 \%$ \\
\hline Extreme gradient boosting & $13.3 \%$ & $46.2 \%$ & $6.0 \%$ & $13.4 \%$ \\
\hline Ordinary least-squares linear regression & $17.2 \%$ & $35.7 \%$ & $6.2 \%$ & $10.3 \%$ \\
\hline Ridge regression & $15.8 \%$ & $32.1 \%$ & $6.3 \%$ & $9.7 \%$ \\
\hline $\begin{array}{l}\text { Least absolute shrinkage and selection } \\
\text { operator }\end{array}$ & $17.2 \%$ & $35.7 \%$ & $5.9 \%$ & $9.3 \%$ \\
\hline Elastic net & $15.8 \%$ & $32.1 \%$ & $6.4 \%$ & $10.1 \%$ \\
\hline Artificial neural network & $13.8 \%$ & $29.8 \%$ & $6.1 \%$ & $8.9 \%$ \\
\hline
\end{tabular}


The performance of machine learning models in stock level heating and cooling energy consumption prediction is presented in Table 4. For the whole stock including both residential and non-residential building, the relative error for heating and cooling at the whole stock level are within $\pm 4 \%$, except for heating prediction of artificial neural

561 network which has a relative error of $-9.7 \%$. Heating energy consumption is more likely 562 to be underestimated, with cooling energy consumption are more likely to be 563 overestimated. The Gaussian radial basis function kernel SVR performed the best with 564 a whole stock level relative error of $-0.2 \%$ and $-0.3 \%$ respectively for heating and 565 cooling prediction. Followed by polynomial kernel SVR, with a whole stock level 566 relative error of $0.3 \%$ and $0.5 \%$ respectively for heating and cooling prediction. It is 567 interesting to note that although the artificial neural network has a high relative error 568 for heating prediction, it performs very well in cooling prediction with a relative error 569 of only $0.2 \%$. For the residential stock, random forests and extreme gradient boosting 570 performed the best in heating and cooling prediction respectively, with relative error of $5710.6 \%$ and $0.1 \%$. For the non-residential stock, linear kernel SVR and polynomial kernel

572 SVR performed the best in heating and cooling prediction respectively, with relative 573 error of $2.0 \%$ and $-1.0 \%$. Meanwhile, all machine learning models studied overestimate 574 space cooling energy consumption for residential stock while underestimate space 575 cooling energy consumption for non-residential stock

576 Table 4: The relative error $\delta_{\text {Stock }}$ of different machine learning models at the stock level 


\begin{tabular}{|l|c|c|c|c|c|c|}
\hline \multirow{2}{*}{$\begin{array}{l}\text { Machine learning } \\
\text { models }\end{array}$} & \multicolumn{2}{|c|}{ Whole stock } & \multicolumn{2}{c|}{ Residential stock } & \multicolumn{2}{c|}{ Non-residential stock } \\
\cline { 2 - 7 } function & $-0.2 \%$ & $-0.3 \%$ & $1.7 \%$ & $0.6 \%$ & $-6.2 \%$ & $-2.4 \%$ \\
\hline $\begin{array}{l}\text { Gaussian radial } \\
\text { basis } \\
\text { kernel SVR }\end{array}$ & Cooling & Heating & Cooling & Heating & Cooling \\
\hline Linear kernel SVR & $1.0 \%$ & $1.1 \%$ & $0.7 \%$ & $2.2 \%$ & $2.0 \%$ & $-1.7 \%$ \\
\hline $\begin{array}{l}\text { Polynomial kernel } \\
\text { SVR }\end{array}$ & $0.3 \%$ & $0.5 \%$ & $2.9 \%$ & $1.1 \%$ & $-7.8 \%$ & $-1.0 \%$ \\
\hline Random forests & $-0.6 \%$ & $-0.8 \%$ & $0.6 \%$ & $1.0 \%$ & $-4.4 \%$ & $-5.0 \%$ \\
\hline $\begin{array}{l}\text { Extreme gradient } \\
\text { boosting least- }\end{array}$ & $2.4 \%$ & $-1.0 \%$ & $5.5 \%$ & $0.1 \%$ & $-7.7 \%$ & $-3.8 \%$ \\
\hline $\begin{array}{l}\text { Ordinary linear } \\
\text { squares } \\
\text { regression }\end{array}$ & $-3.8 \%$ & $1.7 \%$ & $-7.6 \%$ & $3.2 \%$ & $8.2 \%$ & $-2.1 \%$ \\
\hline Ridge regression & $-2.3 \%$ & $0.5 \%$ & $-5.7 \%$ & $1.4 \%$ & $8.8 \%$ & $-1.6 \%$ \\
\hline $\begin{array}{l}\text { Least absolute } \\
\text { shrinkage and } \\
\text { selection operator }\end{array}$ & $-3.8 \%$ & $0.8 \%$ & $-7.6 \%$ & $2.0 \%$ & $8.2 \%$ & $-2.3 \%$ \\
\hline Elastic net & $-2.3 \%$ & $0.6 \%$ & $-5.7 \%$ & $1.8 \%$ & $8.8 \%$ & $-2.6 \%$ \\
\hline $\begin{array}{l}\text { Artificial neural } \\
\text { network }\end{array}$ & $-9.7 \%$ & $0.2 \%$ & $-9.0 \%$ & $0.7 \%$ & $-11.7 \%$ & $-1.2 \%$ \\
\hline
\end{tabular}

577 The running time of applying machine learning models in building heating and cooling

578 EUI prediction is shows in Figure 10, varies from 0.032 seconds for elastic net to 0.769

579 seconds for extreme gradient boosting. All ten machine learning models studied are

580 able to predict the heating and cooling EUI of 110 buildings within 1 second, while

581 using UMI to simulation heating and cooling EUI of one building takes at least 10

582 seconds. The machine learning models can speed up the building heating and cooling

583 EUI prediction for more than 1000 times, the swift speed benefits the large scale

584 building stock energy prediction by greatly reduce the prediction time it takes. The

585 machine learning models' running time and UMI simulation time presented above are

586 based on a ThinkPad personal computer with Intel Core i7-6500U Processor, 8 GB 


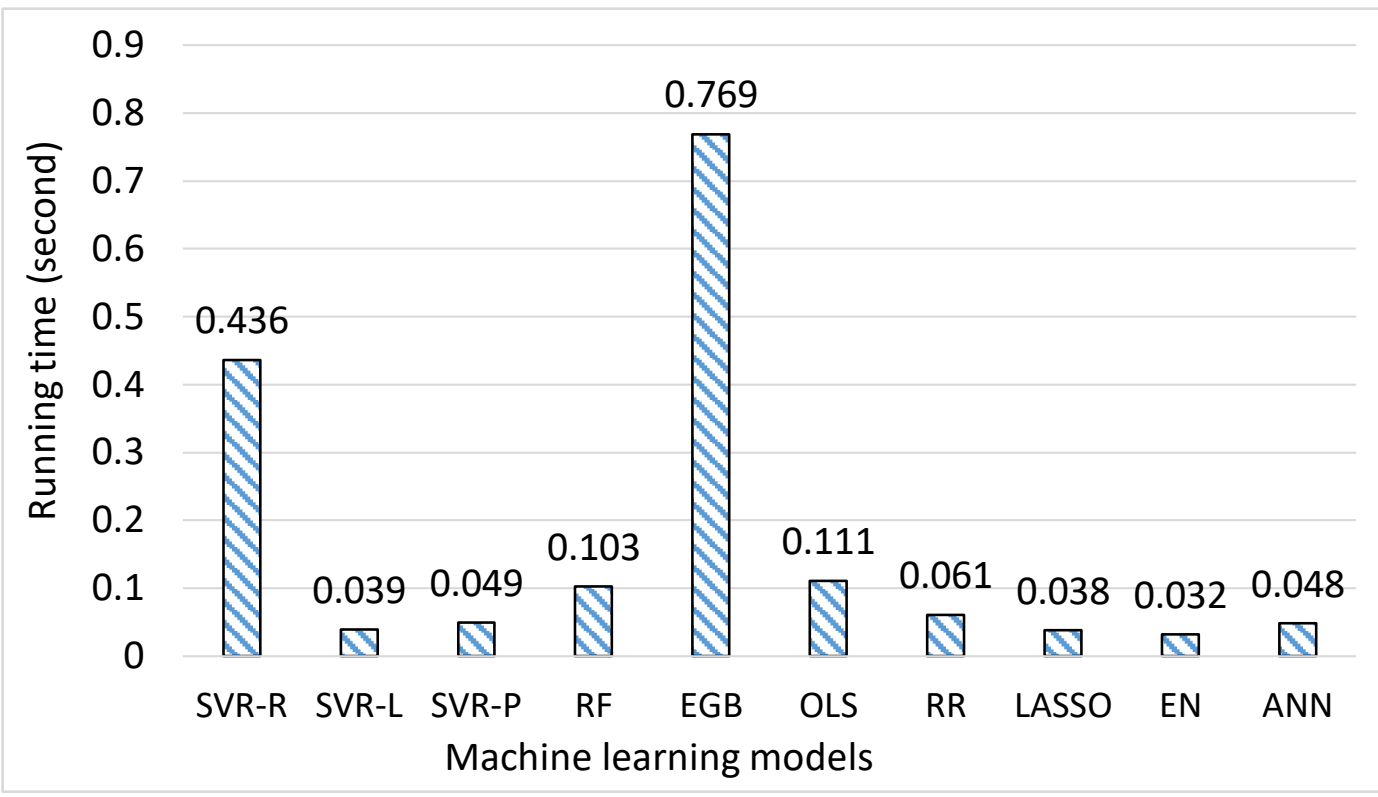

590 Figure 10: The running time of applying machine learning models in building heating 591 and cooling EUI prediction of 110 buildings in testing set(SVR-R: Gaussian radial basis 592 function kernel support vector regression; SVR-L: linear kernel support vector 593 regression; SVR-P: polynomial kernel support vector regression; RF: random forests; 594 EGB: extreme gradient boosting; OLS: ordinary least-squares linear regression; RR: 595 ridge regression; LASSO: least absolute shrinkage and selection operator; EN: elastic 596

\subsection{Evaluation of building stock retrofit energy saving potential}

This section demonstrates the application of machine learning model in building stock retrofit energy saving potential evaluation. As Gaussian radial basis function kernel SVR performed the best at the whole stock level, it is utilized to show the energy saving

601 potential of upgrading building envelopes for entire stock. Assuming to improve the 602 building thermo-physical performance by ensure all buildings' envelope meet the latest 603 standard. The building envelope thermo-physical characteristics for older buildings, 604 including pre-2015 non-residential buildings and pre-2010 residential buildings, after 
Table 5: Assumed building envelope thermal-physical characteristics after retrofit

\begin{tabular}{|c|c|c|c|c|c|c|}
\hline \multirow{3}{*}{$\begin{array}{l}\text { Building } \\
\text { function }\end{array}$} & \multirow{3}{*}{$\begin{array}{c}\text { Construction } \\
\text { age }\end{array}$} & \multicolumn{5}{|c|}{ Building envelope thermal-physical characteristics } \\
\hline & & \multicolumn{4}{|c|}{ U-values $\left(\mathbf{W} / \mathbf{m}^{2} \mathbf{K}\right)$} & \multirow{2}{*}{$\begin{array}{c}\text { Infiltrations } \\
(\mathbf{A C H})\end{array}$} \\
\hline & & Walls & Roof & Slab & $\begin{array}{c}\text { Windows } \\
\text { (U value/SHGC) }\end{array}$ & \\
\hline \multirow{3}{*}{$\begin{array}{c}\text { Non-residential } \\
\text { building }\end{array}$} & Pre-1990 & 0.5 & 0.69 & 0.7 & $2.50 / 0.34$ & 0.15 \\
\hline & $1990-2005$ & 0.5 & 0.69 & 0.7 & $2.50 / 0.34$ & 0.15 \\
\hline & $2005-2015$ & 0.5 & 0.69 & 0.7 & $2.50 / 0.34$ & 0.15 \\
\hline \multirow{2}{*}{$\begin{array}{c}\text { Residential } \\
\text { building }\end{array}$} & Pre-2001 & 0.83 & 0.8 & 1.31 & $2.67 / 0.34$ & 1 \\
\hline & $2001-2010$ & 0.83 & 0.8 & 1.31 & $2.67 / 0.34$ & 1 \\
\hline
\end{tabular}

607 The gross space heating and cooling energy consumption figures for all the buildings

608 in the testing set before and after retrofit are shown in Figure 11. By improving the

609 building envelope, energy consumption reduction is achieved in both space cooling and

610 space heating, with the latter showing a more substantially decrease. The building

611 retrofit performance evaluation using Gaussian radial basis function kernel SVR is

612 straightforward, use the updated U-values and infiltration rates together with other

613 predictor variables which stay unchanged, a swift estimation of the building space

614 heating and cooling demand after retrofit can be achieved. Compared to re-run UMI

615 simulation with updated building envelope thermal-physical characteristics, the

616 machine learning model is faster and less computation intensive. 


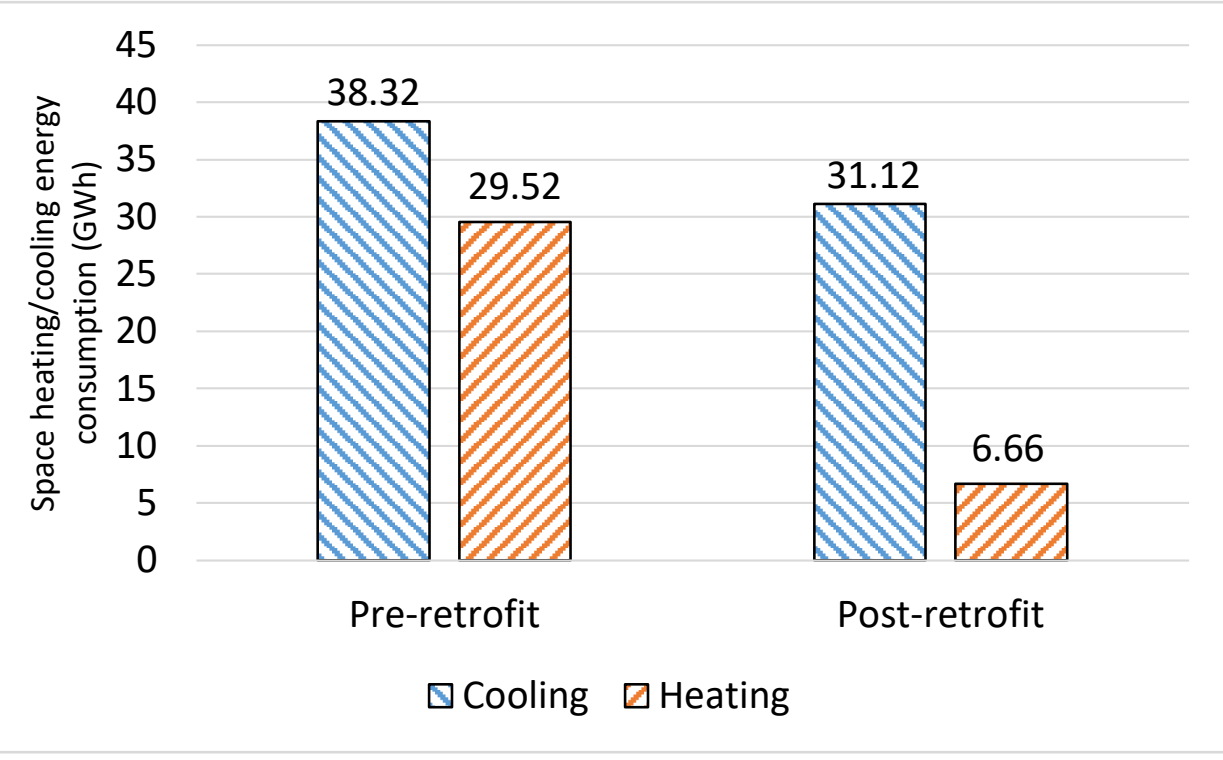

618 Figure 11: The gross space heating and cooling energy consumption before and after 619 retrofit

\section{Discussions and limitations}

621 Starting from training and validation set generated by UMI small scale building stock

622 dynamic simulation, machine learning models are developed via pre-processing and

623 training. The performances of the machine learning models are tested using the UMI

624 generated test set, the comparison shows that machine learning models can replace UMI

625 to predict the heating and cooling energy consumption of single-function buildings in

626 Chongqing with accuracy. Moreover, their swift running time enables potential large-

627 scale building stock energy consumption prediction. The hybrid approach proposed in

628 this study provide a way to give an insight view of the space heating and cooling energy

629 consumption of residential and non-residential building at a large scale building stock.

630 Which helps the understanding of the current energy used in adjust the building indoor 
631 thermal conditions. This provides a solid start point for energy conservation related

632 policy making when the real space heating and cooling energy consumption data is not

633 available due to reasons like lack of monitoring. As detailed building characteristics are

634 used as the predictor variables of the machine learning model, the energy-saving

635 potential of various building retrofit options can be evaluated by the machine learning

636 model. The identification of the best performed retrofit option can support policy

637 making about large scale building stock energy conservation. Moreover, machine

638 learning modelling is easy to use even for people without great knowledge about

639 building thermal physics, so will also be a handy tool for the general public to evaluate

640 the retrofit energy-saving potential of various retrofit options.

641 Although the hybrid approach proposed in this study can predict the building space

642 heating and cooling energy consumption, the lack of public available building energy

643 consumption datasets in Chongqing hinders the validation and calibration of the model

644 to real building energy consumption. The collection of real building energy

645 consumption data remains as a very important task to understand and bridge the

646 performance gap between predicted energy use and actual energy use [105]. Moreover,

647 collecting other building characteristics information, including construction type,

648 construction material, HVAC system, retrofit history record, etc., is also very important

649 in give a true building profile and support building energy consumption calibration.

650 This study also bears the limitation of considering only the single-function buildings,

651 future works should be carried on to collect detail floor area function information and 
652 develop data-driven building energy consumption approach for mixed-use buildings.

\section{6. Conclusions}

654 This study investigated the process of utilizing a hybrid approach to predict building

655 space heating and cooling energy consumption for both residential and non-residential

656 buildings to support large scale building stock energy modelling. Considering the

657 commonly building energy data lacking, the hybrid approach has been used to combine

658 the advantages of both physical modelling and data-driven approaches.

659 Based on the building energy consumption data generated by UMI physical modelling,

660 ten different data-driven machine learning models, including Gaussian radial basis

661 function kernel SVR, linear kernel SVR, polynomial kernel SVR, random forests,

662 extreme gradient boosting, ordinary least-squares linear regression, ridge regression,

663 least absolute shrinkage, and selection operator, elastic net and artificial neural network,

664 have been trained to predict heating and cooling energy use intensity for both residential

665 buildings and non-residential buildings (containing educational buildings, hospitals,

666 hotels, malls, and offices). Building characteristics are utilized as predictor variables of

667 those machine learning models, including geometry characteristics, envelope thermal-

668 physical characteristics, HVAC system characteristics and internal gains characteristics.

669 With known predictor variables, the machine leaning models are able to predict

670 building heating and cooling energy use intensity at individual building level. A case

671 study in Chongqing city (China) has been used to demonstrate the proposed process 
673 summarized as follows:

- Machine learning models can handle both residential and non-residential building energy consumption prediction using a single model, so there is no need to generate multiple models according to different building functions. EUI, with polynomial kernel support vector regression, predicted $85.5 \%$ of building heating EUI within $\pm 10 \%$ of relative error and Gaussian radial basis function kernel support vector regression predicted $91.8 \%$ of building cooling EUI within $\pm 10 \%$ of relative error.

- The polynomial kernel SVR has the best accuracy in the individual building level, with NMAE and NRMSE for heating EUI as $7.3 \%$ and $17.3 \%$ respectively; NMAE and NRMSE for cooling EUI as $4.3 \%$ and $6.2 \%$ respectively. stock level, with a relative error of only $-0.2 \%$ and $-0.3 \%$ respectively for heating and cooling prediction. consumption prediction is more than 1000 times faster than UMI physical modelling, their swift speed proved their potential in large-scale building stock 
693 By integrating physical modelling with data-driven machine learning techniques, the

694 hybrid approach for modelling heating and cooling energy consumption of building

695 stock is no longer rely on the availability of building energy consumption data.

696 Moreover, it can speed up the process of building stock modelling by decrease the

697 number of buildings to be physically simulated and dramatically cutting down the

698 processing time. The generated machine learning model can be applied to quickly

699 predict building space heating and cooling energy consumption at the stock level, as

700 well as evaluate energy saving potential of different building stock retrofit options. This

701 is of great help for building energy conservation related decision makings, it not only

702 provide an insight view of the current space heating and cooling energy consumption

703 when the monitored data is not available, but also able to compare various retrofit

704 measures and select the best one to be implicated in the whole stock. Although the

705 hybrid approach is only demonstrated in Chongqing in this paper, it can be easily

706 replicated in other cities and countries.

\section{Acknowledgements}

708 This research is financially supported by the Natural Science Foundation of China

709 (grant numbers NSFC 51561135002) and the UK Engineering and Physical Sciences

710 Research Council (grant number EPSRC EP/N009797/1) for the collaborative China-

711 UK project LoHCool Low carbon climate-responsive Heating and Cooling of cities. 
712 The authors would like to thank all who participated in the field survey and the

713 comments from Yuxin Wu (Chongqing University) and Vincenzo Costanzo (University

714 of Catania).

\section{References}

716 [1] IEA. Buildings-Tracking Clean Energy Progress. 2019;

717 https://www.iea.org/tcep/buildings/ (Accessed 2019.03.25)

718 [2] European Commission. Buildings. 2019;

719 https://ec.europa.eu/energy/en/topics/energy-efficiency/energy-performance-of-

720 buildings (Accessed 2019.03.25)

721 [3] MOHURD. Building Energy Conservation and Green Building Development 13th

722 Five Year Plan. 2017;

723 http://www.mohurd.gov.cn/wjfb/201703/t20170314_230978.html （Accessed

$724 \quad 2017.3 .23)$

725 [4] X. Zheng, C. Wei, P. Qin, J. Guo, Y. Yu, F. Song, Z. Chen, Characteristics of 726 residential energy consumption in China: Findings from a household survey, Energy 727 Policy, 75 (2014) 126-135.

728 [5] EIA. Heating and cooling no longer majority of U.S. home energy use. 2013; 729 https://www.eia.gov/todayinenergy/detail.php?id=10271\&src=\%E2\%80\%B9\%20Con 730 sumption $\% 20 \% 20 \% 20 \% 20 \% 20 \% 20$ Residential\%20Energy\%20Consumption\%20Sur 731 vey\%20(RECS)-f4 (Accessed 2018.2.18)

732 [6] Department for Business Energy \& Industrial Strategy, Energy consumption in the 733 UK 2017, in, 2017.

734 [7] Eurostat. Energy consumption in households. 2018; $735 \mathrm{http} / / / \mathrm{ec}$. europa.eu/eurostat/statistics-

736 explained/index.php/Energy_consumption_in_households\#cite_note-1 (Accessed $737 \quad 2018.3 .2)$

738 [8] EIA. Energy Use in Commercial Buildings. 2018; 739 https://www.eia.gov/energyexplained/index.php?page=us_energy_commercial\#tab1 740 (Accessed 2019.03.22)

741 [9] M. LI, Influence of Indoor Air Computation Parameter of Civil Building to Heating 742 and Air-Conditioning Energy Consumption, Master, Tianjin University, 2010.

743 [10] BEIS. Building Energy Efficiency Survey (BEES). 2013; 
https://www.gov.uk/government/publications/building-energy-efficiency-survey-bees (Accessed 2019.03.24)

[11] C.F. Reinhart, C.C. Davila, Urban building energy modeling - A review of a nascent field, Building and Environment, 97 (2016) 196-202.

[12] K. Amasyali, N.M. El-Gohary, A review of data-driven building energy consumption prediction studies, Renewable and Sustainable Energy Reviews, 81 (2018) 1192-1205.

[13] J.-S. Chou, D.-K. Bui, Modeling heating and cooling loads by artificial intelligence for energy-efficient building design, Energy and Buildings, 82 (2014) 437-446.

[14] R.K. Jain, K.M. Smith, P.J. Culligan, J.E. Taylor, Forecasting energy consumption of multi-family residential buildings using support vector regression: Investigating the impact of temporal and spatial monitoring granularity on performance accuracy, Applied Energy, 123 (2014) 168-178.

[15] F. Lai, F. Magoulès, F. Lherminier, Vapnik's learning theory applied to energy consumption forecasts in residential buildings, International Journal of Computer Mathematics, 85 (10) (2008) 1563-1588.

[16] J. Ma, J.C.P. Cheng, Identifying the influential features on the regional energy use intensity of residential buildings based on Random Forests, Applied Energy, 183 (2016) 193-201.

[17] J. Ma, J.C.P. Cheng, Estimation of the building energy use intensity in the urban scale by integrating GIS and big data technology, Applied Energy, 183 (2016) 182192.

[18] E. Mocanu, P.H. Nguyen, M. Gibescu, W.L. Kling, Deep learning for estimating building energy consumption, Sustainable Energy, Grids and Networks, 6 (2016) 9199.

[19] S. Naji, A. Keivani, S. Shamshirband, U.J. Alengaram, M.Z. Jumaat, Z. Mansor, M. Lee, Estimating building energy consumption using extreme learning machine method, Energy, 97 (2016) 506-516.

[20] S. Paudel, M. Elmitri, S. Couturier, P.H. Nguyen, R. Kamphuis, B. Lacarrière, O. Le Corre, A relevant data selection method for energy consumption prediction of low energy building based on support vector machine, Energy and Buildings, 138 (2017) 240-256.

[21] L. Wei, W. Tian, E.A. Silva, R. Choudhary, Q. Meng, S. Yang, Comparative Study on Machine Learning for Urban Building Energy Analysis, Procedia Engineering, 121 (2015) 285-292.

[22] U. Ali, M.H. Shamsi, M. Bohacek, K. Purcell, C. Hoare, E. Mangina, J. O’Donnell, 
A data-driven approach for multi-scale GIS-based building energy modeling for analysis, planning and support decision making, Applied Energy, 279 (2020) 115834.

782

783

784

785

786

787

788

789

790

791

792

793

794

795

796

797

798

799

800

801

802

803

804

805

806

807

808

809

810

811

812

813

814

815

[23] H. Deng, D. Fannon, M.J. Eckelman, Predictive modeling for US commercial building energy use: A comparison of existing statistical and machine learning algorithms using CBECS microdata, Energy and Buildings, 163 (2018) 34-43.

[24] B. Dong, C. Cao, S.E. Lee, Applying support vector machines to predict building energy consumption in tropical region, Energy and Buildings, 37 (5) (2005) 545-553.

[25] Q. Li, Q. Meng, J. Cai, H. Yoshino, A. Mochida, Applying support vector machine to predict hourly cooling load in the building, Applied Energy, 86 (10) (2009) 22492256.

[26] Q. Li, Q. Meng, J. Cai, H. Yoshino, A. Mochida, Predicting hourly cooling load in the building: A comparison of support vector machine and different artificial neural networks, Energy Conversion and Management, 50 (1) (2009) 90-96.

[27] S.L. Wong, K.K.W. Wan, T.N.T. Lam, Artificial neural networks for energy analysis of office buildings with daylighting, Applied Energy, 87 (2) (2010) 551-557.

[28] H.X. Zhao, F. Magoulès, Parallel support vector machines applied to the prediction of multiple buildings energy consumption, Journal of Algorithms \& Computational Technology, 4 (2) (2010) 231-249.

[29] T. Liu, Z. Tan, C. Xu, H. Chen, Z. Li, Study on deep reinforcement learning techniques for building energy consumption forecasting, Energy and Buildings, 208 (2020) 109675.

[30] Z. Wang, Y. Wang, R.S. Srinivasan, A novel ensemble learning approach to support building energy use prediction, Energy and Buildings, 159 (2018) 109-122.

[31] F. Zhang, C. Deb, S.E. Lee, J. Yang, K.W. Shah, Time series forecasting for building energy consumption using weighted Support Vector Regression with differential evolution optimization technique, Energy and Buildings, 126 (2016) 94103.

[32] C. Fan, F. Xiao, Y. Zhao, A short-term building cooling load prediction method using deep learning algorithms, Applied Energy, 195 (2017) 222-233.

[33] R. Wang, S. Lu, W. Feng, A novel improved model for building energy consumption prediction based on model integration, Applied Energy, 262 (2020).

[34] S. Walker, W. Khan, K. Katic, W. Maassen, W. Zeiler, Accuracy of different machine learning algorithms and added-value of predicting aggregated-level energy performance of commercial buildings, Energy and Buildings, 209 (2020) 109705.

[35] Y. Wei, X. Zhang, Y. Shi, L. Xia, S. Pan, J. Wu, M. Han, X. Zhao, A review of data-driven approaches for prediction and classification of building energy 
consumption, Renewable and Sustainable Energy Reviews, 82 (2018) 1027-1047.

817 [36] T. Ahmad, H. Chen, Y. Guo, J. Wang, A comprehensive overview on the data

818 driven and large scale based approaches for forecasting of building energy demand: A 819 review, Energy and Buildings, 165 (2018) 301-320.

820 [37] M. Georgescu, E. Eccles, V. Manjunath, E. Swindle, I. Mezi, Machine learning 821 methods for site-level building energy forecasting and data rectification, in: Building

822 Simulation and Optimization-The Second IBPSA-England Conference, 2014.

823 [38] C.E. Kontokosta, C. Tull, A data-driven predictive model of city-scale energy use 824 in buildings, Applied Energy, 197 (2017) 303-317.

825 [39] D. Hawkins, S.M. Hong, R. Raslan, D. Mumovic, S. Hanna, Determinants of 826 energy use in UK higher education buildings using statistical and artificial neural 827 network methods, International Journal of Sustainable Built Environment, 1 (1) (2012) $82850-63$.

829 [40] C. Robinson, B. Dilkina, J. Hubbs, W. Zhang, S. Guhathakurta, M.A. Brown, R.M. 830 Pendyala, Machine learning approaches for estimating commercial building energy 831 consumption, Applied Energy, 208 (2017) 889-904.

832 [41] X. Cheng, Applying Machine Learning Based Data-Driven Approach in 833 Commercial Building Energy Prediction, ASHRAE Transactions, 126 (2020) 403834411.

835 [42] N. Abbasabadi, M. Ashayeri, R. Azari, B. Stephens, M. Heidarinejad, An 836 integrated data-driven framework for urban energy use modeling (UEUM), Applied 837 Energy, 253 (2019) 113550.

838 [43] Y. Pan, L. Zhang, Data-driven estimation of building energy consumption with 839 multi-source heterogeneous data, Applied Energy, 268 (2020).

840 [44] H. Rashid, P. Singh, A. Singh, I-BLEND, a campus-scale commercial and 841 residential buildings electrical energy dataset, Sci Data, 6 (2019) 190015.

842 [45] S. Fathi, R. Srinivasan, A. Fenner, S. Fathi, Machine learning applications in urban 843 building energy performance forecasting: A systematic review, Renewable and 844 Sustainable Energy Reviews, 133 (2020).

845 [46] M. Kavgic, A. Mavrogianni, D. Mumovic, A. Summerfield, Z. Stevanovic, M. 846 Djurovic-Petrovic, A review of bottom-up building stock models for energy 847 consumption in the residential sector, Building and Environment, 45 (7) (2010) 1683 8481697.

849 [47] L.G. Swan, V.I. Ugursal, Modeling of end-use energy consumption in the 850 residential sector: A review of modeling techniques, Renewable and Sustainable Energy 851 Reviews, 13 (8) (2009) 1819-1835. 
[48] M. Brøgger, K.B. Wittchen, Estimating the energy-saving potential in national building stocks - A methodology review, Renewable and Sustainable Energy Reviews, 82 (2018) 1489-1496.

[49] H. Lim, Z.J. Zhai, Review on stochastic modeling methods for building stock energy prediction, Building Simulation, 10 (5) (2017) 607-624.

[50] A. Foucquier, S. Robert, F. Suard, L. Stéphan, A. Jay, State of the art in building modelling and energy performances prediction: A review, Renewable and Sustainable Energy Reviews, 23 (2013) 272-288.

[51] S. Valovcin, A.S. Hering, B. Polly, M. Heaney, A statistical approach for postprocessing residential building energy simulation output, Energy and Buildings, 85 (2014) 165-179.

[52] M. Brøgger, P. Bacher, K.B. Wittchen, A hybrid modelling method for improving estimates of the average energy-saving potential of a building stock, Energy and Buildings, 199 (2019) 287-296.

[53] M. Brøgger, P. Bacher, H. Madsen, K.B. Wittchen, Estimating the influence of rebound effects on the energy-saving potential in building stocks, Energy and Buildings, 181 (2018) 62-74.

[54] X. Li, R. Yao, A machine-learning-based approach to predict residential annual space heating and cooling loads considering occupant behaviour, Energy, 212 (2020) 118676.

[55] G. Ciulla, A. D'Amico, Building energy performance forecasting: A multiple linear regression approach, Applied Energy, 253 (2019) 113500.

[56] X.J. Luo, L.O. Oyedele, A.O. Ajayi, O.O. Akinade, Comparative study of machine learning-based multi-objective prediction framework for multiple building energy loads, Sustainable Cities and Society, 61 (2020) 102283.

[57] S. Goel, H. Horsey, N. Wang, J. Gonzalez, N. Long, K. Fleming, Streamlining building energy efficiency assessment through integration of uncertainty analysis and full scale energy simulations, Energy and Buildings, 176 (2018) 45-57.

[58] Sustainable Design Lab, Umi, in, 2017.

[59] DOE. EnergyPlus Energy Simulation Software. 2017; http://apps1.eere.energy.gov/buildings/energyplus/ (Accessed 2017.12.14)

[60] T. Dogan, C. Reinhart, Shoeboxer: An algorithm for abstracted rapid multi-zone urban building energy model generation and simulation, Energy and Buildings, 140 (2017) $140-153$.

[61] X. Li, R. Yao, M. Liu, V. Costanzo, W. Yu, W. Wang, A. Short, B. Li, Developing urban residential reference buildings using clustering analysis of satellite images, 
889 [62] F. Magoulès, H.-X. Zhao, Data Mining and Machine Learning in Building Energy

890 Analysis: Towards High Performance Computing, John Wiley \& Sons, 2016.

891 [63] H.-x. Zhao, F. Magoulès, A review on the prediction of building energy 892 consumption, Renewable and Sustainable Energy Reviews, 16 (6) (2012) 3586-3592.

893 [64] C. Cortes, V. Vapnik, Support-Vector Networks, Machine Learning, 20 (3) (1995) 894 273-297.

895 [65] R. Tibshirani, G. James, D. Witten, T. Hastie, An introduction to statistical 896 learning-with applications in R, in, New York, NY: Springer, 2013.

897 [66] M. Kuhn, K. Johnson, Applied predictive modeling, Springer, 2013.

898 [67] A.J. Smola, B. Schölkopf, A tutorial on support vector regression, Statistics and 899 Computing, 14 (3) (2004) 199-222.

900 [68] K. Hornik, D. Meyer, A. Karatzoglou, Support vector machines in R, Journal of 901 statistical software, 15 (9) (2006) 1-28.

902 [69] R.I. Kabacoff, R in Action, Second Edition ed., manning, New York, 2015.

903 [70] Y. Zhu, W. Xu, G. Luo, H. Wang, J. Yang, W. Lu, Random Forest enhancement 904 using improved Artificial Fish Swarm for the medial knee contact force prediction, 905 Artificial Intelligence in Medicine, 103 (2020) 101811.

906 [71] A.A. Ahmed Gassar, G.Y. Yun, S. Kim, Data-driven approach to prediction of 907 residential energy consumption at urban scales in London, Energy, 187 (2019).

908 [72] L. Breiman, Random Forests, Machine Learning, 45 (1) (2001) 5-32.

909 [73] T. Hastie, R. Tibshirani, J. Friedman, J. Franklin, The elements of statistical 910 learning: data mining, inference and prediction, The Mathematical Intelligencer, 27 (2) $911 \quad$ (2005) 83-85.

912 [74] T. Chen, C. Guestrin, XGBoost: A Scalable Tree Boosting System, in: 913 Proceedings of the 22nd ACM SIGKDD International Conference on Knowledge 914 Discovery and Data Mining, Association for Computing Machinery, San Francisco, 915 California, USA, 2016, pp. 785-794.

916 [75] XGBoost Documentation. 2020; https://xgboost.readthedocs.io/en/latest/ 917 (Accessed 2020.06.29)

918 [76] T. Chen, T. He, M. Benesty. Xgboost presentation. https://cran.r919 project.org/web/packages/xgboost/vignettes/xgboostPresentation.html (Accessed $920 \quad 2020.06 .29)$

921 [77] S. Touzani, J. Granderson, S. Fernandes, Gradient boosting machine for modeling 

$1533-1543$.

924 [78] T. Chen, T. He, Higgs boson discovery with boosted trees, in: NIPS 2014 workshop on high-energy physics and machine learning, 2015, pp. 69-80.

[79] R.E. Edwards, J. New, L.E. Parker, Predicting future hourly residential electrical consumption: A machine learning case study, Energy and Buildings, 49 (2012) 591928603.

[80] A.E. Hoerl, R.W. Kennard, Ridge Regression: Biased Estimation for Nonorthogonal Problems, Technometrics, 12 (1) (1970) 55-67.

931 [81] R. Tibshirani, Regression Shrinkage and Selection via the Lasso, Journal of the 932 Royal Statistical Society. Series B (Methodological), 58 (1) (1996) 267-288.

933 [82] H. Zou, T. Hastie, Regularization and variable selection via the elastic net, Journal 934 of the Royal Statistical Society: Series B (Statistical Methodology), 67 (2) (2005) 301 935320.

936 [83] Z. Li, J. Dai, H. Chen, B. Lin, An ANN-based fast building energy consumption 937 prediction method for complex architectural form at the early design stage, Building 938 Simulation, 12 (4) (2019) 665-681.

939 [84] B. Lantz, Machine learning with R, Packt Publishing Ltd, 2015.

940 [85] S. Haykin, Neural Networks: A Comprehensive Foundation, Second Edition, 941 Pearson Education, India, 1999.

942 [86] T. Han, A. Siddique, K. Khayat, J. Huang, A. Kumar, An ensemble machine 943 learning approach for prediction and optimization of modulus of elasticity of recycled 944 aggregate concrete, Construction and Building Materials, 244 (2020).

945 [87] D. Geysen, O. De Somer, C. Johansson, J. Brage, D. Vanhoudt, Operational 946 thermal load forecasting in district heating networks using machine learning and expert 947 advice, Energy and Buildings, 162 (2018) 144-153.

948 [88] D. Assouline, N. Mohajeri, J.-L. Scartezzini, Quantifying rooftop photovoltaic 949 solar energy potential: A machine learning approach, Solar Energy, $141 \quad$ (2017) 278950296.

951 [89] MOHURD, Code for design of residential buildings GB 50096-2011, in, Ministry 952 of Housing and Urban-Rural Development, People's Republic of China., 2011.

953 [90] MOHURD, Design code for office building JGJ67-2006, in, 2006.

954 [91] MOHURD, Code for design of school GB50099-2011, in, 2011.

955 [92] MOHURD, Code for design of nursery and kindergarten buildings JGJ39956 2016, in, 2016. 
[93] MOHURD, Code for design of general hospital GB51039-2014, in, 2014.

958 [94] MOHURD, Code for Design of Hotel Building JGJ 62-2014, in, 2014.

959 [95] MOHURD, Code for design of store buildings JGJ48-2014, in, 2014.

960 [96] MOHURD, Design standard for energy efficiency of residential buildings in hot 961 summer and cold winter zone JGJ 134-2001 (in Chinese), in, Ministry of Housing 962 and Urban-Rural Development, People's Republic of China., 2001.

963 [97] MOHURD, Design standard for energy efficiency of residential buildings in hot 964 summer and cold winter zone JGJ 134-2010 (in Chinese), in, Ministry of Housing 965 and Urban-Rural Development, People's Republic of China., 2010.

966 [98] MOHURD, Design code for heating, ventilation and air conditioning GBJ 19-87, 967 in, 1987.

968 [99] MOHURD, Design standard for energy efficiency of public buildings GB50189969 2005, in, Ministry of Housing and Urban-Rural Development, People's Republic of 970 China., 2005.

971 [100] MOHURD, Design standard for energy efficiency of public buildings GB50189972 2015, in, Ministry of Housing and Urban-Rural Development, People's Republic of 973 China., 2015.

974 [101] V. Costanzo, R. Yao, X. Li, M. Liu, B. Li, A multi-layer approach for estimating 975 the energy use intensity on an urban scale, Cities, 95 (2019) 102467.

976 [102] T. Hu, H. Yoshino, Z. Jiang, Analysis on urban residential energy consumption 977 of Hot Summer \& Cold Winter Zone in China, Sustainable Cities and Society, 6 (2013) $978 \quad 85-91$.

979 [103] Y. Lu, Practical Heating and Air Conditioning Design Manual (second edition), 980 China Architecture \& Building Press, Beijing, 2008.

981 [104] M. Kuhn. The caret Package. 2017; http://topepo.github.io/caret/index.html 982 (Accessed 2018.4.17)

983 [105] P. de Wilde, The gap between predicted and measured energy performance of 984 buildings: A framework for investigation, Automation in Construction, 41 (2014) 4098549. 